\title{
Characterization of neuroendocrine tumors in heterozygous mutant MENX rats: a novel model of invasive medullary thyroid carcinoma
}

\author{
Sara Molatore1,*, Andrea Kügler',*, Martin Irmler², Tobias Wiedemann', Frauke Neff'2, Annette Feuchtinger ${ }^{3}$, \\ Johannes Beckers2,4,5, Mercedes Robledo6, Federico Roncaroli7 and Natalia S Pellegata1 \\ 'Institute for Diabetes and Cancer, Helmholtz Zentrum München, Neuherberg, Germany \\ 2Institute of Experimental Genetics, Helmholtz Zentrum München, Neuherberg, Germany \\ ${ }^{3}$ Research Unit Analytical Pathology, Helmholtz Zentrum München, Neuherberg, Germany \\ ${ }^{4}$ German Center for Diabetes Research (DZD), Neuherberg, Germany \\ ${ }^{5}$ Technische Universität München, Chair of Experimental Genetics, Freising, Germany \\ ${ }_{6}^{6}$ Hereditary Endocrine Cancer Group, Spanish National Cancer Research Centre (CNIO) and ISCIII Center for Biomedical Research on Rare Diseases \\ (CIBERER), Madrid, Spain \\ ${ }^{7}$ Division of Neuroscience and Experimental Psychology, Faculty of Medicine, University of Manchester, Manchester, UK \\ Correspondence should be addressed to N S Pellegata: natalia.pellegata@helmholtz-muenchen.de \\ *(S Molatore and A Kügler contributed equally to this work)
}

\begin{abstract}
Rats affected by the MENX syndrome spontaneously develop multiple neuroendocrine tumors (NETs) including adrenal, pituitary and thyroid gland neoplasms. MENX was initially reported to be inherited as a recessive trait and affected rats were found to be homozygous for the predisposing Cdkn1b mutation encoding p27. We here report that heterozygous MENX-mutant rats (p27+/mut) develop the same spectrum of NETs seen in the homozygous (p27mut/mut) animals but with slower progression. Consequently, p27+/mut rats have a significantly shorter lifespan compared with their wild-type (p27+/+) littermates. In the tumors of p27+/mut rats, the wild-type Cdkn1b allele is neither lost nor silenced, implying that p27 is haploinsufficient for tumor suppression in this model. Transcriptome profiling of rat adrenal (pheochromocytoma) and pituitary tumors having different p27 dosages revealed a tissue-specific, dose-dependent effect of p27 on gene expression. In p27+/mut rats, thyroid neoplasms progress to invasive and metastatic medullary thyroid carcinomas (MTCs) accompanied by increased calcitonin levels, as in humans. Comparison of expression signatures of late-stage vs early-stage MTCs from p27+/mut rats identified genes potentially involved in tumor aggressiveness. The expression of a subset of these genes was evaluated in human MTCs and found to be associated with aggressive RET-M918T-positive tumors. Altogether, p27 haploinsufficiency in MENX rats uncovered a novel, representative model of invasive and metastatic MTC exploitable for translational studies of this often aggressive and incurable cancer.
\end{abstract}
Key Words
- MENX
- medullary thyroid cancer
- p27 haploinsufficiency

(c) 2018 Society for Endocrinology Published by Bioscientifica Ltd. Printed in Great Britain
Endocrine-Related Cancer (2018) 25, 145-162 


\section{Introduction}

The cyclin-dependent kinase (CDK) inhibitor p27 is a negative regulator of the cell cycle. It is post-translationally downregulated in over $50 \%$ of human cancers and its low expression is an independent predictor of poor survival for breast, colorectal, prostate, lung, head and neck cancers (Chu et al. 2008). Animal models with defective p27 function have contributed to our understanding of the role of this protein in tumorigenesis and suggested a function as tumor suppressor (Fero et al. 1996, Kiyokawa et al. 1996, Nakayama et al. 1996). Recently, a role for $\mathrm{p} 27$ in the pathogenesis of neuroendocrine tumors (NETs) has emerged. A spontaneous homozygous germline frameshift mutation in $C d k n 1 b$ encoding an unstable p27 protein (Molatore et al. 2010a) causes a multiple endocrine neoplasia (MEN) syndrome in rats known as MENX (Pellegata et al. 2006). MENX-affected rats develop multiple NETs including bilateral pheochromocytoma, multifocal anterior pituitary adenomas, bilateral thyroid C-cell hyperplasia at high penetrance within their first year of life (Fritz et al. 2002). Capitalizing on this discovery, heterozygous germline mutations in CDKN1B were identified in human patients presenting with multiple NETs, the so-called MEN type 4 (MEN4) syndrome (Pellegata et al. 2006). The involvement of p27 in NETs has been further proven by the identification of somatic heterozygous frameshift mutations and hemizygous losses of the CDKN1B gene in NETs of the small intestine (Francis et al. 2013, Crona et al. 2015, Maxwell et al. 2015).

Studies in mice showed that deletion of one Cdkn1b allele is enough to increase the susceptibility to radiationor carcinogen-induced tumorigenesis (Fero et al. 1998). These findings indicate that p27 is haploinsufficient for tumor suppression in mice. The impact of single allele mutations in CDKN1B in humans is still unclear. The available tumors of MEN4 patients lacked p27 expression, indicating complete gene inactivation typical of a canonical tumor suppressor (Lee \& Pellegata 2013). Similarly, reduced or no p27 expression was found in small intestine NETs bearing somatic p27 frameshift mutations (Maxwell et al. 2015). In the MENX syndrome, homozygous mutant rats with loss of p27 expression develop multiple NETs. The phenotype of heterozygous mutant rats has not been characterized so far and is the focus of the present study.

Nonfunctioning pituitary adenomas (NFPAs) represent the second most common type of adenohypophyseal cell tumors with over $70 \%$ of them being gonadotroph adenomas. More than $40 \%$ of NFPAs extend to the cavernous sinus and less commonly invade the sellar floor (Brochier et al. 2010) rendering complete surgical resection very difficult if not impossible. Reported relapse rate of incompletely removed NFPAs is up to $50 \%$. Radiation therapy is the only post-operative option for recurrent NFPA patients, but it is not curative (Pereira \& Biermasz 2012).

Pheochromocytomas originate from chromaffin cells of the adrenal medulla and sympathetic ganglia (the latter are referred to as paragangliomas). They occur sporadically or as a result of an inherited germline mutation in up to $50 \%$ of cases (Dahia 2014). Approximately 10-15\% of pheochromocytomas metastasize to distant organs and the 5-year survival rate of patients with malignant tumors is $<50 \%$ (Eisenhofer et al. 2004). Surgery remains the first-line therapy for patients with localized disease or with isolated and resectable distant metastases. No effective therapies are currently available for patients with disseminated disease.

Medullary thyroid carcinoma (MTC) accounts for $5-7 \%$ of all thyroid carcinomas but is responsible for a disproportionately high number of deaths compared to follicular and papillary carcinomas due to its aggressive behavior (Woyach \& Shah 2009). MTC often metastasizes to lymph nodes early in the course of the disease, and spread to distant organs is common (Rendl et al. 2008). Advanced stage of tumor progression at diagnosis and the presence of lymph node metastases are the most critical poor prognostic factors (Wells et al. 2012). Surgery is the elective treatment of MTC with high curative rates for stage I, II and III tumors. For patients with locally advanced or metastatic MTC, systemic treatment is the only option, but it is not curative (Cabanillas et al. 2016). Improvement in progression-free survival of patients with advanced MTC treated with the tyrosine kinase inhibitors vandetanib and cabozantinib was observed (Kurzrock et al. 2011, Durante et al. 2013) but without significant improvement in overall survival (Wells et al. 2012, Elisei et al. 2013). Moreover, these agents associate with severe secondary toxicities. Thus, novel therapies are sought after to improve the outcome in patients with aggressive MTC.

About 25\% of MTCs occur in the setting of the MEN type 2 (MEN2) and familial MTC syndromes and are caused by mutations of the REarranged during Transfection (RET) gene encoding a tyrosine kinase transmembrane receptor (Romei et al. 2016). MEN2 is divided into three subtypes (MEN2A, MEN2B, FMTC) according to the aggressiveness of the tumors, time of onset and the presence of endocrine 
tumors in addition to MTC (Raue \& Frank-Raue 2009). MEN2A is associated with mutations in cysteine (Cys) residues and particularly with the Cys634 (C634) residue. The more aggressive MEN2B variant is almost exclusively associated with a mutation at methionine 918, i.e. the Met918Thr (M918T) alteration (reviewed in Romei et al. 2016). The most frequent somatic alteration in sporadic MTC is RET-M918T. This mutation (either germline or somatic) correlates with a more aggressive clinical course (Elisei et al. 2008). A variable percentage of sporadic MTC cases (from 0 to $40 \%$ of cases depending on the study) are associated to somatic mutations in RAS (Romei et al. 2016). A role for cell cycle regulatory genes (e.g. $\mathrm{Rb}$ and CDK inhibitors) in the pathogenesis of sporadic MTCs has also been suggested (Vitale et al. 2017).

Animal models are essential to elucidate the pathomechanisms of tumor initiation and progression and to identify and evaluate novel therapies. Our previous studies have shown that homozygous mutant MENX rats can be used to model gonadotroph adenoma (Lee et al. 2013, Marinoni et al. 2013) and pheochromocytoma (Molatore et al. 2010b). These tumors develop with complete penetrance in MENX rats and share several features with the corresponding human tumors. MENX rats have therefore been exploited for preclinical studies evaluating the efficacy of novel drugs, which provided us with the rationale for the clinical implementation of compounds inhibiting PI3K and mTOR (Lee et al. 2015, 2017).

Currently, there are several preclinical models of MTC, the majority of them being transgenic mice overexpressing mutated RET oncogenes to recapitulate the human MEN2 syndrome (Wiedemann \& Pellegata 2016). Conditional overexpression in parafollicular C-cells of the $p 25$ gene, a cofactor of cyclin-dependent kinase 5 (Cdk5), promotes MTC (Pozo et al. 2013). Xenograft models obtained by inoculating MTC cell lines in immunocompromised mice may be used to test novel antitumor agents, but they do not recapitulate the tumor microenvironment and the interactions between stroma and cancer cells. Alternative models such as Drosophila, chick embryo chorioallantoic membrane and zebrafish are promising tools to investigate the molecular basis of MTC and angiogenesis, as well as to perform highthroughput drug screening, but each system has specific limitations (reviewed in Vitale et al. 2017).

In this study, we have investigated heterozygous mutant MENX rats (p27+/mut) and compared them to homozygous mutant (p27mut/mut) animals. Heterozygous animals spontaneously develop multiple NETs over time with a spectrum overlapping that of $\mathrm{p} 27 \mathrm{mut} / \mathrm{mut}$ rats. Tumors of $\mathrm{p} 27+/$ mut rats retain the wild-type $C d k n 1 b$ allele suggesting that $\mathrm{p} 27$ is haploinsufficient for tumor suppression in this model. p27+/mut rats spontaneously develop invasive and metastatic MTC that is pathologically and biochemically similar to human MTC. Transcriptome analysis of advanced rat MTCs identified genes potentially involved in tumor progression, which were validated in a series of human MTCs and found to associate with the more aggressive RET-M918T mutation-positive tumors. The genes identified in our model have never been studied in MTC and represent novel putative biomarkers of aggressive disease.

\section{Materials and methods}

\section{Animals and genotyping}

The MENX phenotype was originally identified in a Sprague-Dawley (SD) rat colony and affected rats were indicated SDwe (white eye) because they present with juvenile cataracts (Fritz et al. 2002). The rat phenotype is maintained by crossing heterozygous mutant rats and the current MENX rats derive from more than 10 generations of intercrosses. Animals are hosted in agreement with general husbandry rules approved by the Helmholtz Zentrum München and by the local government (Bayerische Landsregierung). They were killed with carbon dioxide in compliance with institutional requirements and necropsied.

The position of the $C d k n 1 b$ mutation identified in affected MENX rats and the predicted sequence of the encoded mutant p27 protein are illustrated in Supplementary Fig. $1 \mathrm{~A}$ and $\mathrm{B}$ (see section on supplementary data given at the end of this article). Genotyping was performed by amplifying genomic DNA extracted from rat tail tips with the DNeasy extraction kit (Qiagen) using previously reported primers spanning the site of the mutation (a 8-bp insertion in exon 2 of $C d k n 1 b$ ) (Pellegata et al. 2006). The PCR product was then resolved by polyacrylamide gel electrophoresis (Supplementary Fig. 1C).

\section{Patient samples}

We evaluated 21 human frozen MTC samples, collected at the Spanish National Cancer Research Centre (CNIO) in collaboration with CNIO Tumor Bank. All patients provided written informed consent. The study was 
approved by the Instituto de Salud Carlos III Institutional Review Board.

\section{Pathological examination}

Tissues from MENX rats were fixed in $4 \%$ buffered formalin and routinely processed to paraffin-embedding. Three micrometer sections were cut and stained with hematoxylin and eosin (H\&E), Gomori's silver impregnation for reticulin fibers and Masson's trichrome. Two experienced pathologists ( $\mathrm{F} \mathrm{N}$ and $\mathrm{F} \mathrm{R}$ ) reviewed all normal rat tissues and tumors.

\section{RNA isolation and microarray preparation}

Pituitary, adrenal and thyroid glands from rats of the three genotypes were snap-frozen in liquid nitrogen and stored at $-80^{\circ} \mathrm{C}$ until used. Serial cryosections of the organs obtained from p27+/mut and p27mut/mut rats were made and the first one was stained with hematoxylin and eosin (H\&E) to identify the tumor areas. Subsequent sections were macrodissected under a stereomicroscope (adrenal and pituitary glands) or microdissected (thyroid gland) to obtain the hyperplastic/tumor areas using a PALM-microdissection system (Zeiss). Lesions with similar histology were dissected from all tumor samples of p27+/mut or p27mut/mut rats. Macrodissection was done well within tumor margin to avoid contamination with normal adjacent cells. RNA was extracted from these dissected tissues or from normal pituitary or adrenomedullary tissues of wild-type rats using standard protocols (Molatore et al. 2010b).

For array analysis, total rat RNA (30 ng) was amplified using the Ovation PicoSL WTA System V2 in combination with the Encore Biotin Module (Nugen, Leek, The Netherlands). Amplified cDNA was hybridized on Affymetrix Rat Gene 1.0 ST arrays (Affymetrix). Staining and scanning were done according to the Affymetrix expression protocol including minor modifications as suggested in the Encore Biotin protocol.

For Ret gene sequencing, cDNA was obtained by reverse-transcription from RNA extracted from 9 MTCs of p27+/mut rats. We synthesized the first-strand cDNA by using random hexamers and SuperScript II (Invitrogen). Sequencing of exons 10,11, 13, 14, 15 and 16, known to carry activating mutations in humans, was performed using previously reported primers (De Miguel et al. 2003) with the BigDye terminator kit (Applied Biosystems), and sequences were run on an ABI377 sequencer (Applied Biosystems).

\section{Biostatistical and bioinformatic array analysis}

Expression console (Affymetrix) was used for quality control and to obtain annotated normalized RMA genelevel data (standard settings including median polish and sketch-quantile normalization). Statistical analyses were performed by utilizing the statistical programming environment $R$ ( $R$ Development Core Team 2011) implemented in CARMAweb (Rainer et al. 2006). Genewise testing for differential expression was done employing the limma $t$ test and Benjamini-Hochberg multiple testing correction (FDR $<10 \%$ ). The following filters were used to define sets of regulated genes: $P<0.01$ (limma $t$ test), foldchange $>2 \times$ (adrenal, Supplementary Dataset 1 ); FDR $<10 \%$, fold-change $>2 \times$ (pituitary, Supplementary Dataset 2); FDR $<10 \%$, fold-change $>3 \times$, average expression in at least one of three groups $>100$ (thyroid, Supplementary Dataset 3). Level 3 Biological Process Gene Ontology (GO) terms were created using WebGestalt GSAT (www.webgestalt.org) and subsequently the Superfamily (www.supfam.org) free software (Fig. 5). Array data are available at NCBI/GEO with the accession numbers GSE53365 (adrenal), GSE29457 (pituitary) and GSE98546 (thyroid).

\section{Comparison of expression profiles of human and rat MTCs}

Lists of genes significantly regulated between RET-M918T and RET-WT (FC $\geq 3 \times$, FDR $<15 \%$ ) human MTC samples were previously reported (Maliszewska et al. 2013). Updated gene symbols were used to match these genes to the set of genes regulated in lesions of thyroid tissue of 18-month-old p27+/mut (HET-18M) vs 9-month-old p27+/mut (HET-9M) MENX rats (FDR $<10 \%$, fold-change $>1.5 \times$, average expression >100; without Het_18M_13549/12931). Genes with opposite regulation in the rat and human datasets were removed. Generanker software (Genomatix, Munich, Germany) was used to obtain GO terms associated with the 26 concordantly dysregulated genes reported in Table 2 . A non-stringent $P$ value cut-off $(P<0.1)$ was used and terms with less than three regulated genes were excluded.

\section{Quantitative (q)TaqMan RT-PCR}

qRT-PCR was performed using TaqMan inventoried primers and probes for the genes indicated in the article (PLA2G16, SMAD9, HSPB1, CLDN3, GREM2, NREP, GRHL3, TUBB2B, TUBB6, CA10) (Applied Biosystems). The relative mRNA expression level of the target genes 
A

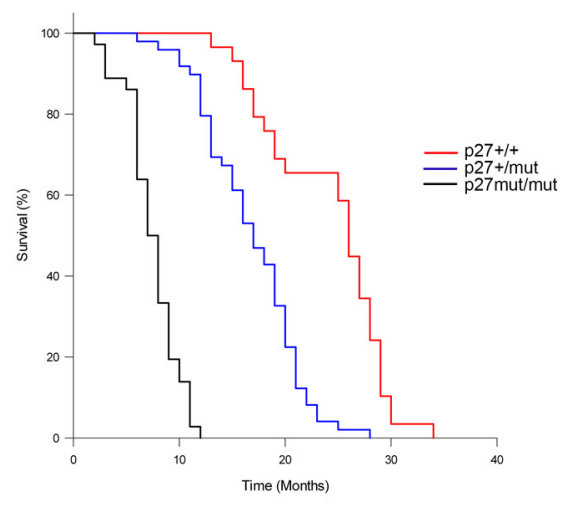

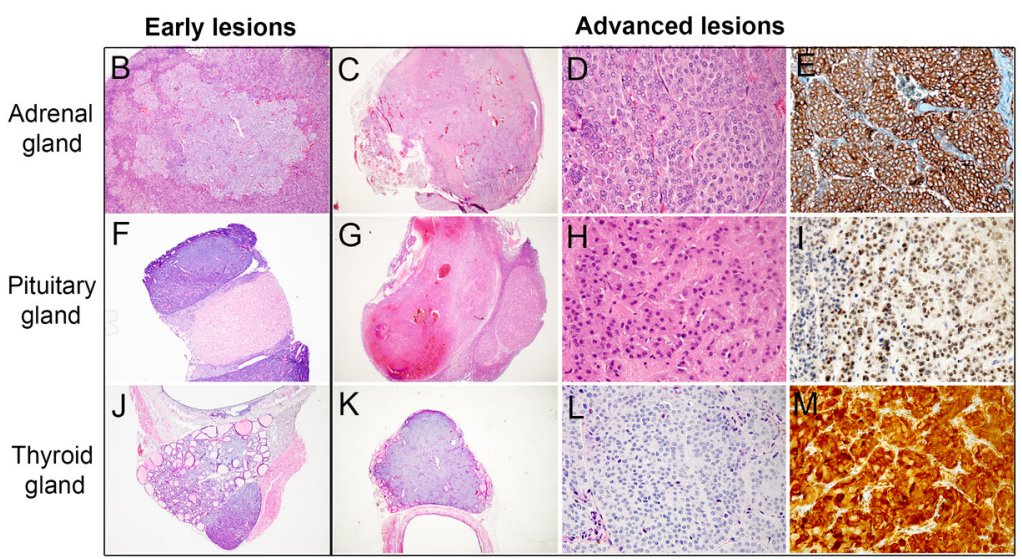

\section{Figure 1}

Phenotypic features of p27+/mut and p27mut/mut MENX rats. (A) The overall survival of p27+/+, p27+/mut and p27mut/mut rats is shown. Survival curves are Kaplan-Meier plots censored for deaths due to noncancerous causes. Hematoxylin and eosin (H\&E) staining of adrenal ( $B, C$ and $D)$, pituitary $(\mathrm{F}, \mathrm{G}$ and $\mathrm{H})$ and thyroid (J, K and L) glands of p27+/mut rats showing lesions at different stages. Original magnification: $B, \mathrm{~F}, \mathrm{~J}$ : $40 \mathrm{x} ; \mathrm{C}, \mathrm{G}, \mathrm{K}$ : 20x; $\mathrm{D}, \mathrm{H}, \mathrm{L}$ : 400x. (E, I, M) Immunohistochemistry of advanced lesions with antibodies against L1CAM (E), SF1 (I) and calcitonin (M). Original magnification: 400x.

was normalized for input RNA using human TBP gene expression (housekeeping gene) and was calculated with the $2-\Delta \Delta \mathrm{Ct}$ formula. Data were analyzed independently with six replicates each and are expressed as the mean \pm s.E.M.

\section{DNA extraction and analysis}

Pituitary adenomas were microdissected from frozen sections using a PALM-microdissection system (Zeiss) and DNA was extracted using the DNeasy extraction kit (Qiagen). Primers to amplify the mutation in the $C d k n 1 b$ gene were previously reported (Pellegata et al. 2006).

\section{Immunohistochemistry}

Tissue sections were dewaxed in xylene and decreasing alcohols. Antigen retrieval was performed with $10 \mathrm{mM}$ sodium citrate buffer at $\mathrm{pH} 6$ in the microwave for $30 \mathrm{~min}$. Endogenous peroxidase was quenched with $0.3 \%$ $\mathrm{H}_{2} \mathrm{O}_{2}$ for $5 \mathrm{~min}$. The sections were washed twice in TBS, incubated with blocking solution for $30 \mathrm{~min}$ and then with the primary antibody overnight at $4^{\circ} \mathrm{C}$. The primary antibodies (Supplementary Table 1) were diluted in Dako REAL buffer (Dako). The anti-p27 antibody is raised against the full-length mouse protein and can recognize the mutated p27 protein in fibroblasts derived from MENX rats (Molatore et al. 2010a). The supersensitive detection system (BioGenex, Freemont, CA, USA) was used and the immunoreactions developed in the DAB supplied with the kit. Washes between each step were done in TBS. Appropriate positive and negative controls were run in parallel to confirm the adequacy of the staining.

\section{Quantitative analysis of Ki67 immunohistochemical staining (IHC)}

Tissue sections were scanned for quantitative analysis using NanoZoomer 2.0-HT scanner (Hamamatsu Photonics Deutschland, Herrsching am Ammersee, Germany). The regions of interest were identified for each of the digital slides and analyzed using commercially available software (Definiens Enterprise Image Intelligence Suite, Definiens AG, Munich, Germany). Ki67-positive cell nuclei were automatically detected and scored using the 'Definiens TissueMAP 3.01' tool.

\section{Calcitonin measurements}

Blood from fasted rats was collected in EDTA tubes. Plasma was isolated by centrifugation and stored at $-20^{\circ} \mathrm{C}$. Calcitonin levels were measured with the Rat Calcitonin EIA Kit (Phoenix Pharmaceuticals, Burlingame, CA, USA) according to the manufacturer's protocols.

\section{Statistics}

Life expectancy was plotted using Kaplan-Meier statistics and significance was determined using the log-rank (Mantel-Cox) test. Array statistical analyses were performed with the programming environment $\mathrm{R}$ implemented in CARMAweb (Rainer et al. 2006) as indicated earlier. Pairwise comparisons of TaqMan data were performed by 2-tailed Student's $t$ test using Excel. Data are expressed as the mean \pm s.e.m. $P$ values less than 0.05 were considered significant. 
Table 1 Incidence of spontaneous lesions in the indicated organs of rats of the reported genotypes and age ranges.

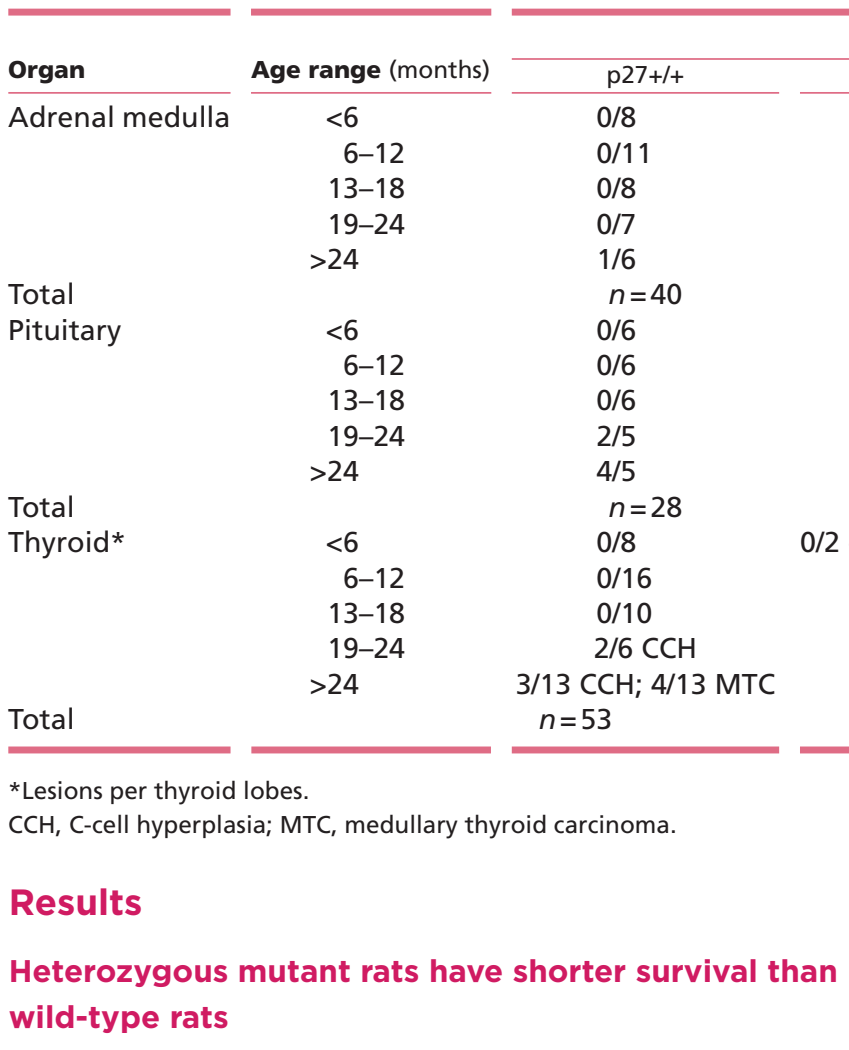

We investigated 49 heterozygous (p27+/mut), 36 homozygous (p27mut/mut), 29 wild-type (p27+/+) littermates. Heterozygous mutant rats survived an average of 512 days (maximum 852 days), whereas p27mut/mut animals had an average survival of 243 days (maximum 354 days). Wild-type rats lived 740 days on average (maximum 1034 days) (Fig. 1A). The cumulative survival curves showed that the life expectancy of p27+/mut rats was significantly longer than that for homozygous rats $\left(P=5.2 \mathrm{e}^{-20}\right)$ but significantly shorter than that for wildtype littermates $\left(P=1.7 \mathrm{e}^{-7}\right)$ (Fig. 1A). Increased intracranial pressure due to the considerable volume of pituitary adenomas and/or hypertension and associated multi-organ failure caused by the pheochromocytomas (Wiedemann \& Pellegata 2016) are the most likely causes of the premature death of the p27mut/mut rats. Blood pressure data are currently not available for the $\mathrm{p} 27+/$ mut rats.

\section{Histopathological characterization of tumors in heterozygous mutant rats}

We performed necropsy and histological examination of all animals. Both p27+/mut males and females developed multiple NETs including bilateral pheochromocytomas, multifocal pituitary adenomas and MTC with
$100 \%$ penetrance. The tumor spectrum overlapped that of p27mut/mut animals. Tumor progression in p27+/mut animals was followed in adrenal, pituitary and thyroid glands. Specimens were collected at different time points during the animals' lifespan (as indicated below) and analyzed histologically. The frequency of histologically detectable lesions in rats of the three $C d k n 1 b$ genotypes over their life span is summarized in Table 1 and the morphology of the selected organs over time is illustrated in Supplementary Figs 2, 3 and 4.

Tumors in the adrenal glands were detected as early as 5-6 months of age while increase in size and weight of the glands and macroscopically visible nodules were only detectable from 12 months (Fig. 1B, C and D). By 16 months, pheochromocytomas reached up to $7-8 \mathrm{~mm}$ in size, entirely replaced the medulla and compressed and displaced the normal cortex. Similar to homozygous mutant animals (Molatore et al. 2010b), neoplastic cells in p27+/mut rats expressed L1CAM (Fig. 1E) but were negative for phenylethanolamine $\mathrm{N}$-methyltransferase (PNMT), the enzyme responsible for the conversion of noradrenalin to adrenalin (Supplementary Fig. 5). Representative adrenals from rats of the three genotypes at different ages are shown in Supplementary Fig. 2.

Histologically detectable lesions in the pituitary gland of p27+/mut rats occurred at 5-6 months compared to 4 months in p27mut/mut rats (Fig. 1F, G and H). Lesions were macroscopically visible from the age of 16 months (Supplementary Fig. 3). As observed in p27mut/mut 

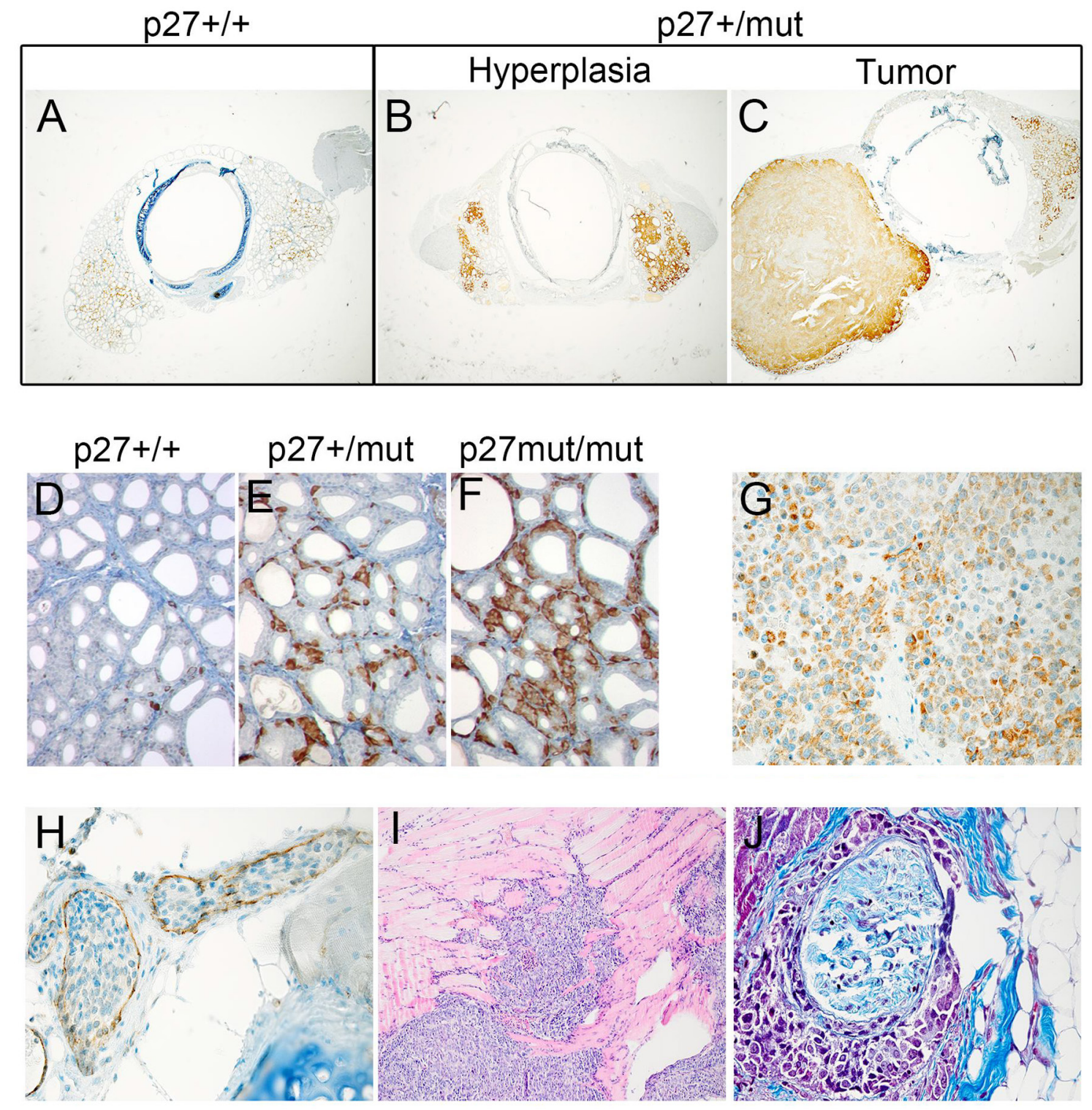

Figure 2

Characterization of rat thyroid lesions. Expression of calcitonin in thyroid glands of $\mathrm{p} 27+/+(\mathrm{A})$ and $\mathrm{p} 27+/$ mut $(\mathrm{B}$ and $\mathrm{C})$ rats. Original magnification: $20 \mathrm{x}$. Expression of calcitonin in thyroid glands of 2-month-old p27+/+ (D), p27+/mut (E) and p27mut/mut (F) rats. Original magnification: 200x. (G) Expression of calcitonin in a liver metastasis of a MTC in a p27+/mut rat. Original magnification: 400x. (H, I and J) Invasion of MTCs of p27+/mut rats in vasculature $(H)$, muscles $(I)$ and nerves $(J)$. CD31 (H), H\&E (I) and Masson's trichrome stainings (J) were performed. Original magnification: I, 100x; H, J: 400x.

rats, pituitary adenomas of p27+/mut animals were immunoreactive for the gonadotroph-specific transcription factor SF1 (Fig. 1I) and for the common gonadotropin alpha-subunit ( $\alpha \mathrm{GSU})$ (Supplementary Fig. 6A). Similar to p27mut/mut rats (Marinoni et al. 2013), the expression of FSH $\beta$ and LH $\beta$ subunits was present in the early lesions but was progressively lost (Supplementary Fig. 6A and data not shown). Adenomas in $277_{+} /$mut rats showed oncocytic changes, which were not present in p27mut/mut animals (Supplementary Fig. 6B). However, no oncocytomas, defined as having oncocytic features in $>50 \%$ of neoplastic cells (Lloyd et al. 2004), were found. While the pituitary adenomas that occur in p27+/mut and p27mut/mut rats are morphologically very similar and derive from gonadotroph cells, spontaneous adenomas developing in aged p27+/+ rats were almost always lactotroph adenomas (Supplementary Fig. 7), in agreement with previously reported data on spontaneous pituitary tumors in Sprague-Dawley rats (McComb et al. 1984).

In the thyroid, p27+/mut rats developed bilateral calcitonin-positive (Fig. 1M) and thyroglobulin-negative 


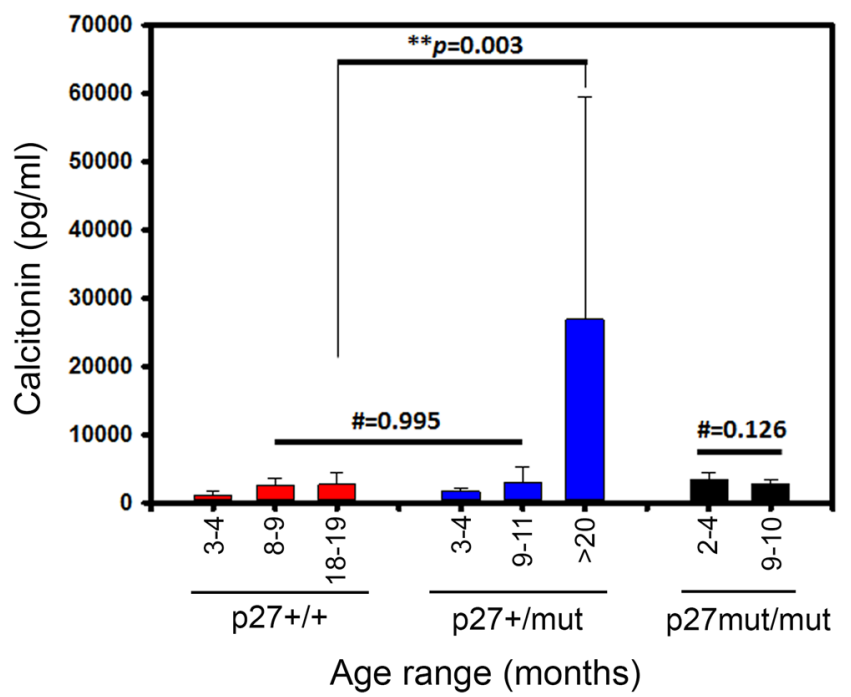

Figure 3

Circulating levels of calcitonin. The levels of blood calcitonin were measured by ELISA in p27+/+, p27+/mut and p27mut/mut rats at the indicated ages. The number of animals was $n=6$ per group. The genotype of the rat groups is reported. Shown is the mean (in pg/mL) \pm S.E.M. \#Not significant; ${ }^{* * P}=0.003$.

(Supplementary Fig. 8) lesions. They showed bilateral focal C-cell hyperplasia (CCH) already at 2 months of age, which progressed to diffuse and then nodular $\mathrm{CCH}$ between 6 and 16 months of age and ultimately to MTC (mostly unilateral) (Figs 1J, K, L, 2 and Supplementary Fig. 4). Focal CCH was the earliest detectable microscopic pathological change in these animals and occurred from 2 months of age (Fig. 2D, E and F), while lesions of the adrenal medulla and adenohypophysis appeared after 5 months. In p27+/mut rats older than 16 months of age, MTCs progressed to a size of up to $5 \mathrm{~mm}$ and effaced the gland (Fig. 2C), leaving only a few residual normal follicles displaced at the periphery of the tumor. Vascular, muscular and/or perineural invasion was a common feature in large tumors (Fig. 2H, I and J). A few animals older than 18 months also developed liver metastases (Fig. 2G). Rat MTCs were morphologically similar to their human counterpart. Calcitonin levels paralleled the increase in tumor size, in p27+/mut rats, with values up to $>10$-fold higher in rats older than 20 months (Fig. 3). This is reminiscent of patients with MTC where calcitonin levels correlate with tumor burden (Cohen et al. 2000). Given the pivotal role of RET in the development of human MTC, we sequenced the regions of the Ret gene corresponding to those where activating mutations occur in humans, in nine MTCs derived from $\mathrm{p} 27+/$ mut rats, but no mutations were found (data not shown).
Aged Sprague-Dawley rats have been reported to spontaneously develop lesions in the thyroid consisting mainly of C-cell adenomas with an incidence varying from 3\% to $8 \%$ depending on the study (Chandra et al. 1992, Nakazawa et al. 2001). Indeed, we observed CCH and a few MTCs in p27+/+ rats older than 22 months (Table 1) but the size of their tumors was much smaller than in p27+/mut rats of 20-24 months of age (Supplementary Fig. 9).

\section{p27 expression is retained in heterozygous rat tumors}

Expression of p27 in normal tissues of p27+/mut rats was reduced when compared with the same tissues of $\mathrm{p} 27+/+$ animals (Supplementary Fig. 10) due to rapid degradation of the p27 mutant protein (Molatore et al. 2010a). Nuclear p27 expression in tumors of p27+/mut rats was similar to the adjacent normal tissue (Supplementary Fig. 10) indicating retention of the wild-type $C d k n 1 b$ allele. One of 8 microdissected pituitary adenomas that were analyzed at genomic level showed loss of the wildtype p27 allele (12\%), which correlated with lack of p27 expression (Fig. 4). These data suggest that biallelic $C d k n 1 b$ inactivation is infrequent in $\mathrm{p} 27+/$ mut rats and that p27 is haploinsufficient for tumor suppression in the MENX model.

\section{p27 dosage and cell proliferation}

p27 expression negatively correlates with proliferation in various human normal and tumor tissues. To assess the potential effect of $C d k n 1 b$ gene-dosage on cell proliferation in the MENX model, we determined the Ki67 labeling index of selected tissues from rats of the three $C d k n 1 b$ genotypes. In the adrenal gland, at 2 months of age, the highest proliferation rate was seen in the nonpathological medulla of p27mut/mut animals (>6\%) with a decreasing gradient in p27+/mut (4\%) and p27+/+ animals (1\%) (Supplementary Fig. 11A). The Ki67 labeling index increased to $9 \%$ in the pheochromocytomas of 6-month-old p27mut/mut, whereas it did not increase in age-matched p27+/mut rats. In tumors of 19-monthold p27+/mut animals, the percentage of Ki67-positive cells reached 14\% (Supplementary Fig. 11A and B). Such proliferative activity is remarkable considering that human pheochromocytomas usually show rates lower than 6\% (Ohji et al. 2001).

At two months of age, adenohypophyseal cells showed similarly low proliferation rates regardless of the 
A
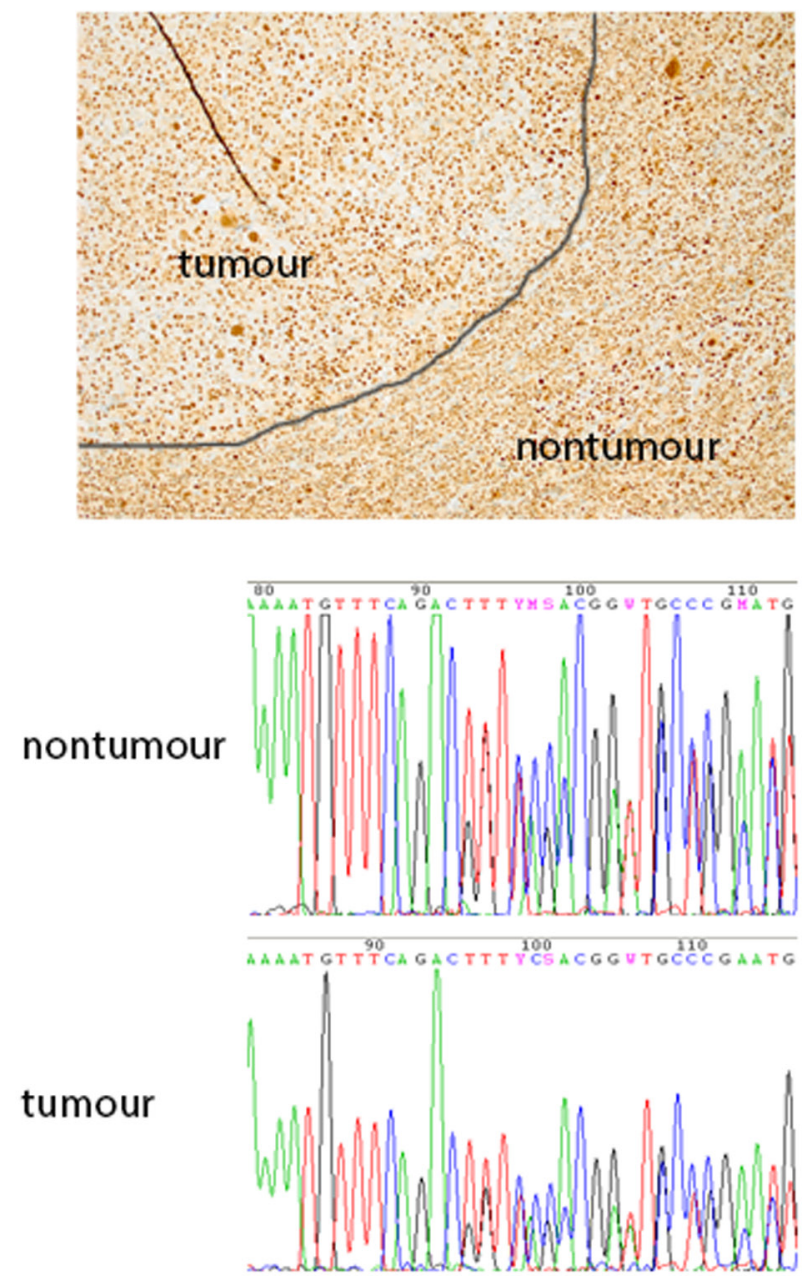

B

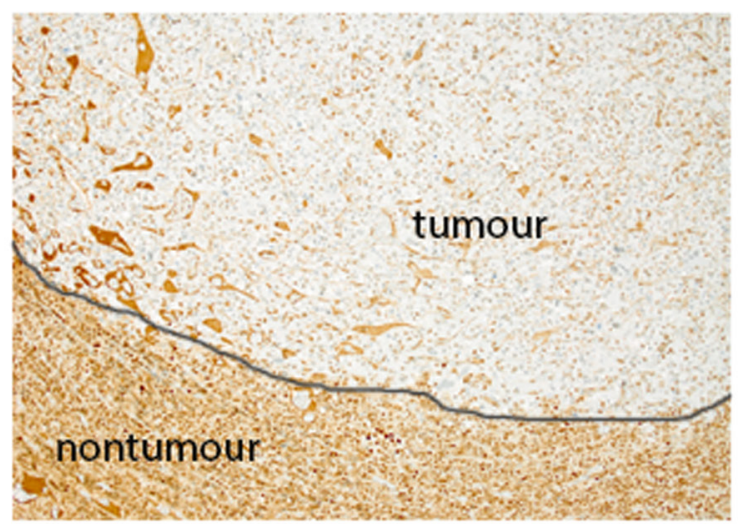

nontumour

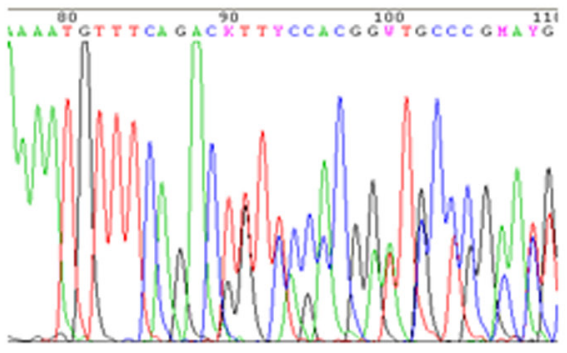

tumour

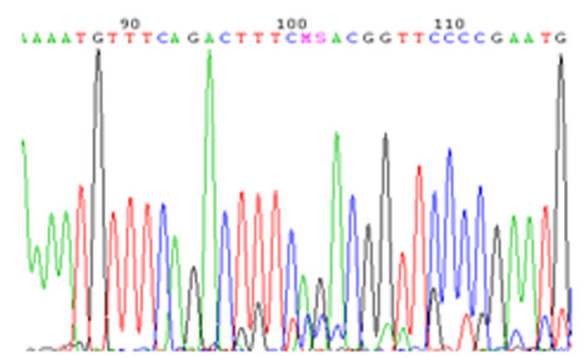

Figure 4

Expression of p27 and DNA analysis in pituitary adenomas of p27+/mut rats. (A) Example of a rat adenoma retaining p27 expression. DNA was extracted from the tumor and from the adjacent non-tumorous area, and sequenced using primers for the rat Cdkn1b gene. Chromatograms corresponding to the indicated tissue areas are shown below, and indicate that both alleles (wild-type and mutant) are present in both areas. (B) The only rat adenoma (out of 8) with loss of p27 expression. Chromatograms corresponding to the indicated tissue areas show that the mutant allele is present in both areas while the signal for the wild-type allele is extremely reduced in the tumor indicating loss-of-heterozygosity (LOH).

Cdkn1b genotype (Supplementary Fig. 11A). The average Ki67 labeling index in pituitary adenomas of 6-monthold p27mut/mut rats was $12 \%$ against $1 \%$ in pituitaries of p27+/mut and p27+/+ rats. The number of Ki67-positive cells increased to $8 \%$ in the large adenomas of 19 -monthold p27+/mut animals (Supplementary Fig. 11A).

Since parafollicular C-cells are few in normal thyroid tissue and scattered among a vast majority of follicular cells, in young rats, we did not assess their proliferation by Ki67 staining. Instead, we looked at calcitonin expression. The number of calcitonin-positive cells in both p27mut/mut and p27+/mut rats was already elevated at 2 months compared to age-matched wild-type animals (Fig. 2D, E and F). Ki67 immunostaining was however performed on diffuse $\mathrm{CCH}$ and large MTCs in p27+/mut rats. This analysis revealed that MTCs have very high proliferation rates (15-35\%) when compared to $\mathrm{CCH}$ (4.4\%) (Supplementary Fig. 12). Interestingly, the few MTCs we identified in very old $\mathrm{p} 27+/+$ rats have much lower Ki67 labeling index (3.95\%) than those in old p27+/mut animals (Supplementary Fig. 12).

The liver, an organ unaffected by the Cdkn1b mutation, was investigated in parallel as control tissue and showed similar Ki67 labeling index across the three genotypes (Supplementary Fig. 11A and B). http://erc.endocrinology-journals.org https://doi.org/10.1530/ERC-17-0456 (c) 2018 Society for Endocrinology Published by Bioscientifica Ltd. Printed in Great Britain 
A p27+/mut vs. p27+/+

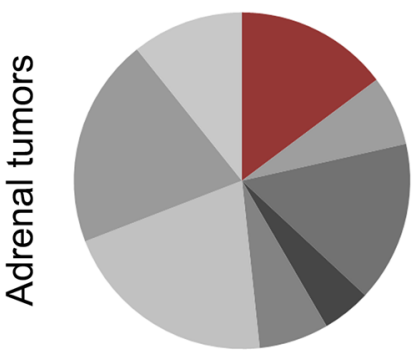

B

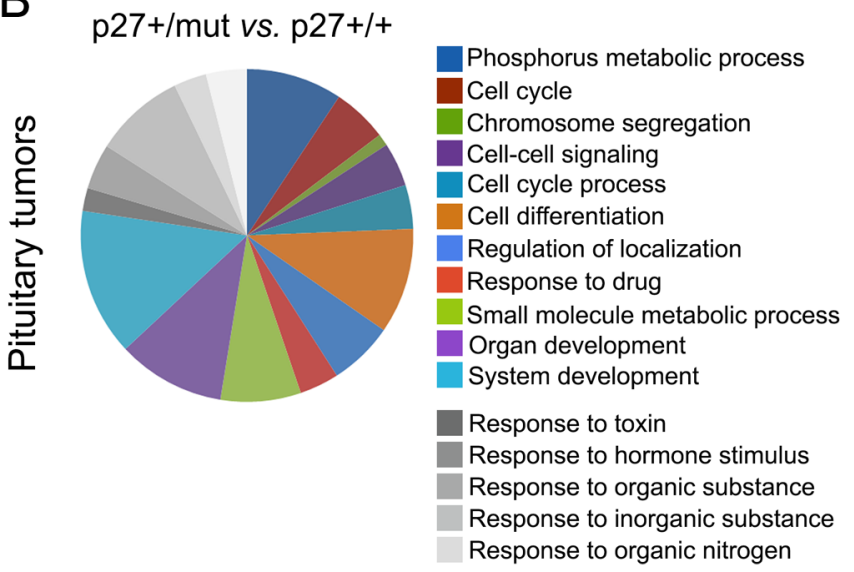

Cell differentiation

Blood vessel development

Cell death

Response to mechanical stimulus

Response to inorganic substance

Regulation metabolic process

Regulation biological process p27mut/mut vs. p27+/+

Cellular response chemical stimulus

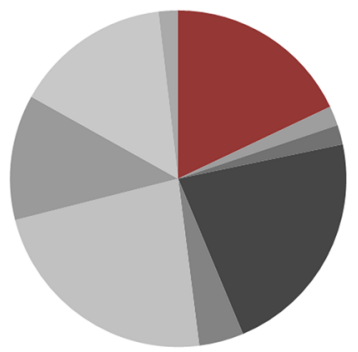

Cell differentiation

Outflow tract morphogenesis

Cardiac septum development

Regulation biological processes

Embryonic organ development

System development

Regul. developmental process

Regul. multicellular organism

Cardiac septum morphogenesis

p27mut/mut vs. p27+/+

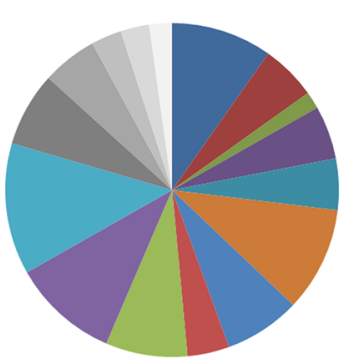

Phosphorus metabolic process

Cell cycle

Chromosome segregation

Cell-cell signaling

Cell cycle process

Cell differentiation

Regulation of localization

Response to drug

Small molecule metabolic process

Organ development

System development

Organonitrogen metabolism

Regulation molecular function

Signal involved in cell-cell signals

Regulation hormone levels

Epithelial cell proliferation

Figure 5

Gene expression signature of adrenal and pituitary tumors in p27+/mut and p27mut/mut MENX rats. (A and B) Most enriched Gene Ontology (GO) categories in rat adrenal and pituitary tumors. (A) Level 3 Biological Process $\mathrm{GO}$ annotations identified by comparing the p27+/mut with the p27+/+ dataset (left) and the p27mut/mut with the p27+/+ dataset (right) for the adrenal glands. (B) Level 3 Biological Process GO annotations identified by comparing the p27+/mut with the p27+/+ dataset (left) and the p27mut/mut with the p27+/+ dataset (right) for the pituitary gland. In colors are illustrated the GO terms in common between the 'p $27+/$ mut vs p $27+/+$ ' and the 'p 27 mut/mut vs p $27+/+$ ' datasets in adrenal or pituitary tissues. In different shades of gray are illustrated the GO terms not shared in the above indicated comparisons.

Transcriptome analysis reveals a tissue-specific, dose-dependent effect of p27 on gene expression

To assess whether NETs developing in p27+/mut and p27mut/mut rats follow similar molecular pathways, we profiled the globalgeneexpression of pheochromocytomas, pituitary adenomas and MTCs. Samples obtained from p27+/mut or p27mut/mut rats used for the comparisons were of similar histology.

\section{Pheochromocytomas}

Gene expression signatures of 7 tumors from p27+/mut rats (age 16-22 months) were compared with those of 4 normal adrenal medullas from age-matched p27+/+ rats. A >2-fold increased expression of 29 genes was observed in neoplastic vs normal tissues, whereas 53 genes were underexpressed (FDR <10\%, Av >100; Supplementary Dataset 1). To obtain a functional annotation of the expression signature, we performed Gene Ontology (GO) category enrichment for the significantly upregulated or downregulated genes using the WebGestalt software. Genes related to cell death $\left(P=3.15 \mathrm{e}^{-8}\right)$ and blood vessel development $\left(P=2.0 \mathrm{e}^{-4}\right)$ were overrepresented in tumors of p27+/mut rats vs wild-type rat adrenals (Fig. 5A). In contrast, pheochromocytomas of p27mut/mut rats have an overrepresentation of developmentassociated pathways (Fig. 5A), as previously reported (Molatore et al. 2010b). Therefore, pheochromocytomas developing in p27+/mut or p27mut/mut rats only share 'cell differentiation' as dysregulated GO category (1 out of 16), suggesting that tumors arising in the context of different dosages of functional p27 have different genetic signatures.

\section{Pituitary adenomas}

Transcriptome analysis of 8 microdissected pituitary adenomas from 5 p27+/mut rats (age 19-22 months) was compared with that of 5 normal pituitaries from 
age-matched p27+/+ animals. A $>2$-fold increased expression in tumors vs normal pituitary was seen for 840 genes, whereas 713 genes were underexpressed (FDR $<10 \%$, Av >100; Supplementary Dataset 2). Among the genes significantly differentially expressed, we found by pathway analysis an overrepresentation of those related to cell cycle $\left(P=7.5 \mathrm{e}^{-5}\right)$, cell-cell signaling $\left(P=1.7 \mathrm{e}^{-3}\right)$, cell differentiation $\left(P=1.2 \mathrm{e}^{-3}\right)$ and organ development $\left(P=1.0 \mathrm{e}^{-3}\right)$ (Fig. 5B). The expression signature of pituitary adenomas arising in p27+/mut or p27mut/mut rats (vs normal pituitary) (Lee et al. 2013) was remarkably similar with 11 out of $21 \mathrm{GO}$ categories being shared by both tumor groups (Fig. 5B).

\section{Medullary thyroid carcinomas}

Transcriptome profiling was performed on MTCs from p27+/mut rats at about 9 and 18 months of age (range 9-11 and 18-20 months, respectively) and from p27mut/mut rats at about 9 months of age (range 9-11 months). The lack of normal C-cells as normalizing reference prevented us from comparing normal and neoplastic tissue. Since no significant differences were seen between the genetic profile of 9 -month-old p27+/mut rats vs age-matched p27mut/mut animals (Supplementary Table 2), we compared late- vs early-stage tumors in 18- and 9-monthold p27+/mut rats, respectively. This analysis identified 364 probe sets with a $>3$-fold increased expression in 18-month-old compared with 9-month-old animals and 50 probe sets with a $>3$-fold decreased expression (FDR $<10 \%$, Av > 100; Supplementary Dataset 3). Enrichment of GO categories related to system development $\left(P=4.45 \mathrm{e}^{-25}\right)$, cell projection organization $\left(P=1.58 \mathrm{e}^{-15}\right)$ and cell-cell signaling $\left(P=1.18 \mathrm{e}^{-12}\right)$ was observed in advanced rat MTCs by pathway analysis (Supplementary Table 3).

\section{Comparison between rat and human MTC}

Considering the lack of spontaneous animal models of MTC, we determined whether the rat tumors recapitulate human MTCs. The gene expression signature of human MTC is driven by the presence and type of RET mutations (Jain et al. 2004, Maliszewska et al. 2013, Oczko-Wojciechowska et al. 2017), with RET-M918Tpositive tumors showing activation of pathways involved in invasion and metastasis (Maliszewska et al. 2013). In p27+/mut rats older than 18 months, MTCs reached a considerable size, they were always locally invasive and occasionally metastatic, and they showed high proliferation rates (Supplementary Fig. 12). Thus, we consider tumors in these animals as more aggressive than the lesions $(\mathrm{CCH})$ observed in 9-month-old heterozygous rats. We then compared the gene expression signature of more aggressive tumors with that of less aggressive ones in both rat (18-month-old vs 9-month-old dataset) and human samples (RET-M918T vs RET-WT dataset). We found genes concordantly dysregulated in both datasets (i.e. in both species), which encode proteins involved in signal transduction, intracellular transport, metabolic processes, cell-cell interaction, cytoskeleton organization (Table 2 and Supplementary Table 4). None of these genes has been investigated in human MTC so far.

To verify whether these genes are indeed differentially expressed in human tumors, a subset was validated by quantitative (q) RT-PCR in samples with a different RET status (RET-WT, RET-C634, RET-M918T) (Table 3). The following genes were selected based on their fold-change (in both rat and human datasets): PLA2G16, SMAD9, HSPB1, CLDN3, GREM2, NREP, GRHL3, TUBB2B, TUBB6 and $C A 10$. Considering the in silico expression array analysis, TUBB2B, GREM2, NREP, TUBB6, CA10 and GRHL3 should be upregulated in RET-M918T vs RET-WT human MTCs and PLA2G16, SMAD9, HSPB1 and CLDN3 should be downregulated (Table 2). TUBB2B and NREP were significantly more expressed in RET-M918T than in RET-WT human tumors, whereas TUBB6, CA10 and GREM2 showed a similar, albeit not significant, trend (Fig. 6). HSPB1 and CLDN3 were downregulated in RET-M918T vs RET-WT tumors, with only HSPB1 reaching statistical significance, whereas PLA2G16 and SMAD9 were only mildly underexpressed (Fig. 6). Interestingly, these 4 downregulated genes were more highly expressed in RET-C634 MTCs than in the other tumor groups (Fig. 6). GRHL3 had a very low expression across the samples and is therefore not shown. Altogether, advanced MTCs in heterozygous rats share gene expression signatures with aggressive human RET-M918T-positive MTCs.

\section{Discussion}

We demonstrate here that heterozygous mutant MENX rats develop NETs similar to the homozygous animals but have a significantly longer life span. Pheochromocytomas and pituitary adenomas in p27+/mut rats morphologically resemble those occurring in p27mut/mut animals. The expression signature of tumors from animals with a different dosage of p27 was similar in pituitary adenomas but differed in pheochromocytomas. Unlike p27mut/mut animals that mainly show parafollicular $\mathrm{CCH}, \mathrm{p} 27+/$ mut rats develop locally invasive and metastatic MTC. 
Table 2 Genes concordantly dysregulated in the rat (HET-18 months vs HET-9 months) and human (RET-M918T vs RET-WT) datasets.

\begin{tabular}{|c|c|c|c|c|c|}
\hline Symbol or ID* & Gene description & Probe set & $\begin{array}{l}\text { Rat HET-18M vs HET-9M } \\
\text { FC } \geq 1.5 \times, \text { FDR }<10 \%\end{array}$ & Human M918T vs WT & Human symbol \\
\hline Pla2g16 & Phospholipase A2, group XVI & 10713538 & -2.7 & -4.71 & PLA2G16 \\
\hline Aldh6a1 & $\begin{array}{l}\text { Aldehyde dehydrogenase } 6 \text { family, } \\
\text { member } A 1\end{array}$ & 10891120 & -1.8 & -4.02 & ALDH6A1 \\
\hline Raph1 & $\begin{array}{l}\text { Ras association (RalGDS/AF-6) and } \\
\text { pleckstrin homology domains } 1\end{array}$ & 10928452 & -1.6 & -4.00 & RAPH1 \\
\hline Mpp5 & $\begin{array}{l}\text { Membrane protein, palmitoylated } 5 \\
\text { (MAGUK p55 subfamily member } 5 \text { ) }\end{array}$ & 10885500 & -1.7 & -3.96 & MPP5 \\
\hline Zbtb20 & Zinc finger and BTB domain containing 20 & 10754116 & -2.1 & -3.90 & ZBTB20 \\
\hline Sord & Sorbitol dehydrogenase & 10839254 & -1.9 & -3.88 & SORD \\
\hline Pde7b & Phosphodiesterase 7B & 10717069 & -2.0 & -3.78 & PDE7B \\
\hline Steap2 & STEAP family member 2 , metalloreductase & 10853401 & -1.6 & -3.66 & STEAP2 \\
\hline Smad9 & SMAD family member 9 & 10815436 & -3.8 & -3.62 & SMAD9 \\
\hline Snta1 & Syntrophin, alpha 1 & 10850918 & -1.8 & -3.60 & SNTA1 \\
\hline Prkci & Protein kinase $\mathrm{C}$, iota & 10822644 & -2.1 & -3.60 & PRKCI \\
\hline Rnf217 & Ring finger protein 217 & 10702342 & -2.2 & -3.53 & RNF217 \\
\hline Hspb1 & Heat shock protein 1 & 10761128 & -3.5 & -3.52 & HSPB1 \\
\hline Cldn3 & Claudin 3 & 10763184 & -2.6 & -3.49 & CLDN3 \\
\hline Cbr1 & Carbonyl reductase 1 & 10750320 & 2.6 & 3.48 & CBR1 \\
\hline Tubb2b & Tubulin, beta 2B class Ilb & 10794824 & 3.2 & 3.49 & TUBB2B \\
\hline Enah & Enabled homolog (Drosophila) & 10770412 & 1.7 & 3.54 & ENAH \\
\hline Grem2 & Gremlin 2 & 10770117 & 2.2 & 3.57 & GREM2 \\
\hline Ints4 & Integrator complex subunit 4 & 10708785 & 2.0 & 3.59 & INTS4 \\
\hline Nrep & Neuronal regeneration related protein & 10803692 & 2.0 & 3.79 & NREP \\
\hline Tubb6 & Tubulin, beta 6 class V & 10802422 & 2.3 & 3.83 & TUBB6 \\
\hline Trib2 & Tribbles homolog 2 (Drosophila) & 10889263 & 1.5 & 3.86 & TRIB2 \\
\hline Ca10 & Carbonic anhydrase 10 & 10737450 & 4.9 & 3.95 & CA10 \\
\hline Tmtc4 & $\begin{array}{l}\text { Transmembrane and tetratricopeptide } \\
\text { repeat containing } 4\end{array}$ & 10786042 & 1.9 & 4.00 & TMTC4 \\
\hline Elovl2 & ELOVL fatty acid elongase 2 & 10794609 & 1.8 & 4.20 & ELOVL2 \\
\hline Grhl3 & Grainyhead-like 3 (Drosophila) & 10880627 & 1.5 & 4.26 & GRHL3 \\
\hline
\end{tabular}

*In bold are indicated the genes analyzed by TaqMan qRT-PCR in human MTC samples.

HET, heterozygous; WT, wild-type.

\section{Comparison between heterozygous and homozygous mutant MENX rats}

We have shown that $\mathrm{p} 27+/$ mut rats represent a novel spontaneous model of NETs. The MENX syndrome was first reported to be recessively inherited by Fritz and coworkers (Fritz et al. 2002). By identifying the susceptibility gene for MENX, we confirmed that the condition is driven by a germline homozygous mutation in $C d k n 1 b$ (Pellegata et al. 2006). The mutant allele encodes a highly unstable and rapidly degraded p27, resulting in lack of protein expression (loss of function) (Molatore et al. 2010a). Accordingly, the normal tissues of $\mathrm{p} 27+/$ mut rats have reduced amount of p27 compared with the corresponding tissues of wild-type animals. The decreased p27 levels do not result in increased cell proliferation in the pituitary glands of young p27+/mut rats, and only in a modest increase in adrenal glands. Proliferation rates only rise at the time of tumor formation. In the thyroid gland, $\mathrm{CCH}$ is seen already at 2 months of age in both p27+/mut and p27mut/mut rats, thereby being the earliest morphological change in affected tissues.

The global transcriptome profile of tumors derived from $\mathrm{p} 27+/ \mathrm{mut}$ and $\mathrm{p} 27 \mathrm{mut} / \mathrm{mut}$ rats suggests that there is a dose-dependent effect of p27 on gene expression, which is tissue specific: it is evident in adrenal but not in pituitary glands. Functional annotations showed that the pituitary adenomas arising in both tumor groups share most of the enriched GO categories for the genes significantly differentially expressed between tumor and normal tissue, whereas the adrenal tumors in heterozygous or homozygous mutant rats only share $1 \mathrm{GO}$ category out of 16 . Loss of one functional p27 allele in the pituitary therefore directs acinar cells toward a specific gene expression signature, which is similar when both alleles are non-functional. In contrast, the lack of one or both functional p27 alleles in adrenomedullary cells 
Table 3 Human MTC samples used for qRT-PCR validation.

\begin{tabular}{llll}
\cline { 1 - 1 } Sample ID & RET status & & Other features \\
\cline { 1 - 1 } MTC1 & WT & Sporadic \\
MTC2 & WT & Sporadic \\
MTC3 & WT & N/A \\
MTC4 & WT & Sporadic \\
MTC5 & WT & Sporadic \\
MTC6 & WT & Sporadic \\
MTC7 & WT & Sporadic \\
MTC8 & M918T & Sporadic \\
MTC9 & M918T & Sporadic \\
MTC10 & M918T & Sporadic \\
MTC11 & M918T & Sporadic \\
MTC12 & M918T & N/A \\
MTC13 & C634 & Familiar \\
MTC14 & C634 & Familiar \\
MTC15 & C634 & Familiar \\
MTC16 & C634 & Familiar \\
MTC17 & C634 & Familiar \\
MTC18 & C634 & Familiar \\
MTC19 & C634 & Familiar \\
MTC20 & C634 & Familiar \\
MTC21 & C634 & Familiar \\
\hline
\end{tabular}

N/A, not available.

promotes different transcriptional regulatory programs. In models of quiescent mouse fibroblasts, p27 was shown to interact with transcription factors and regulatory proteins to indirectly repress the transcription of genes involved in RNA splicing, mitochondrial organization and respiration, translation and cell cycle (Pippa et al. 2012). In mouse exocrine pancreas, p27 suppresses the transcription of Sox9, a gene involved in acinar-to-ductal metaplasia (Jeannot et al. 2015). Similar to these models, p27 might therefore act as transcriptional regulator in neuroendocrine cells and such regulatory function could be dose dependent and tissue specific. A dose-dependent behavior has been demonstrated for transcription factors such as SF-1 (Doghman et al. 2013) and Oct-3/4 (Niwa et al. 2000).

\section{p27 haploinsufficiency}

We proved one functional p27 allele in MENX rats to be insufficient to prevent neuroendocrine tumorigenesis, making of the syndrome a prototype disease caused by a haploinsufficient tumor suppressor. Our findings strengthen the hypothesis that reduction of p27 is enough to promote tumor formation. Heterozygous knockout mice, upon $\gamma$-irradiation or treatment with carcinogens, develop tumors at higher frequency and multiplicity compared with their wild-type littermates, but at a slower rate than homozygous knockout animals, indicating that the loss of one $C d k n 1 b$ allele already predisposes mice to tumor formation (Fero et al. 1998). Deletion of one $C d k n 1 b$ allele in the background of $\mathrm{Rb}+/-$ and $\mathrm{p} 18-/-$ mice leads to more aggressive endocrine tumors, attesting to a cooperative action of these genes in endocrine tumorigenesis (Park et al. 1999, Franklin et al. 2000).

It has been suggested that retaining p27 function, at least in the cytoplasm, might be advantageous to some tumor cells. While the nuclear function of p27 (inhibition of cyclin-CDK complexes, transcriptional regulation) is mostly tumor suppressive, its role in the cytoplasm is oncogenic as it was found to promote migration, invasion and autophagy (Bencivenga et al. 2017). In support to this hypothesis, p27+/- mice are more susceptible than p27-/- mice to develop mammary and prostate tumors (Muraoka et al. 2002, Gao et al. 2004), whereas mice expressing the mostly nuclear $\mathrm{p} 27^{\mathrm{S} 10 \mathrm{~A}}$ variant are in part resistant to urethane-induced carcinogenesis (Besson et al. 2006). In the MENX model, the presence of one mutant $C d k n 1 b$ allele does not seem to increase spontaneous tumorigenesis when compared to animals with 2 mutant alleles. Tumor spectrum and multiplicity are similar in p27+/mut and p27mut/mut rats, but in the former the tumors, especially in pituitary and adrenal glands, have a slightly delayed onset and progress more slowly.

In patients, hemizygous loss of p27 has been observed in hematopoietic malignancies where it occurs in the absence of inactivation of the wild-type allele (Sato et al. 1995). Recently, heterozygous somatic mutations of CDKN1B with a frequency ranging from $3.5 \%$ to $8.5 \%$ (Francis et al. 2013, Crona et al. 2015, Maxwell et al. 2015), hemizygous deletions (14\%; Francis et al. 2013) and copy number variations (3.4\%; Maxwell et al. 2015) have been identified in small intestine NETs. A subset of $C D K N 1 B$ mutation-bearing small intestine tumors was analyzed for p27 expression by immunohistochemistry. In a study, the presence of presumed pathogenic mutations did not correlate with the level of expression of the protein (Crona et al. 2015), whereas Maxwell and coworkers (Maxwell et al. 2015) reported loss of p27 expression in samples carrying frameshift $C D K N 1 B$ mutations. Most tumor tissues of MEN4 patients (bearing a germline CDKN1B mutation) do not express the protein, suggesting a canonical tumor suppressor role for p27 (Lee \& Pellegata 2013). The analysis of additional mutation-positive tumors is required to reach conclusive evidence about the putative haploinsufficient role of p27 in human NETs. 
TUBB2B

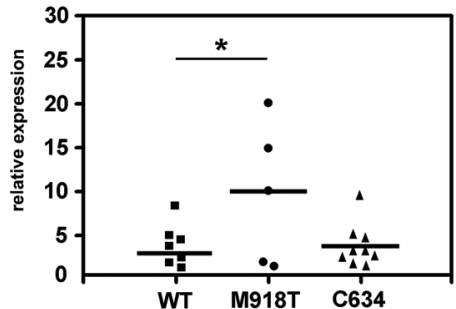

CA10

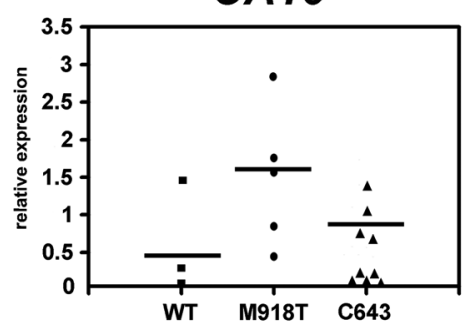

PLA2G16

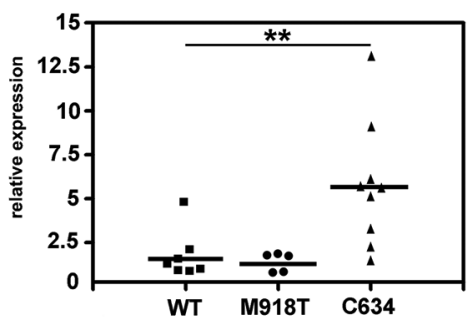

NREP

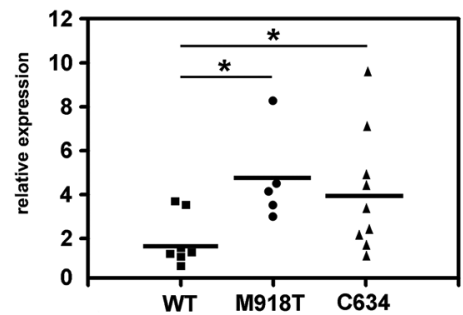

GREM2

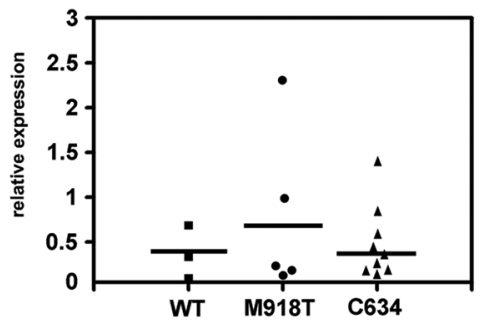

CLDN3

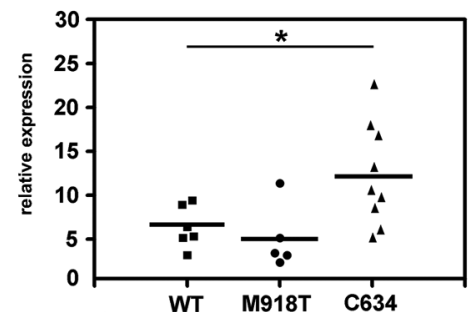

TUBB6

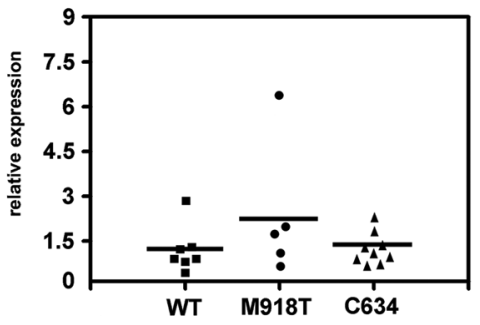

HSPB1

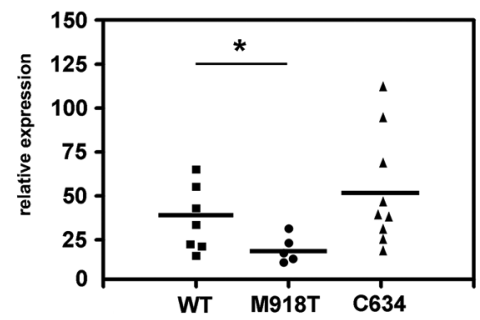

SMAD9

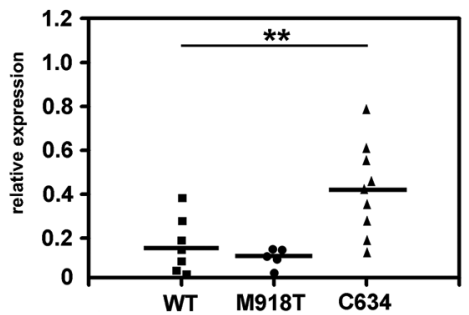

Figure 6

Expression of selected differentially expressed genes in human MTCs. qRT-PCR for TUBB2B, NREP, TUBB6, CA10, GREM2, HSPB1, PLA2G16, CLDN3 and SMAD9 was performed on human MTC samples with different RET mutation status (Table 2). The relative mRNA expression level of the target genes was normalized for input RNA using TBP as housekeeping gene and was calculated with the $2^{-\triangle \Delta C t}$ formula. Data were analyzed independently with six replicates each and are expressed as the mean \pm S.E.M. Only the comparisons leading to a statistical significance are indicated in the graphs. WT, wild-type; $* P<0.05 ; * * P<0.01$.

\section{p27+/mut rats are a discovery platform for novel}

\section{MTC-associated genes}

MENX heterozygous mutant rats develop large, invasive and metastatic MTCs. Rat tumors are histologically identical to the human counterpart. Moreover, p27+/mut rats share with the human tumors high levels of circulating calcitonin that increase with tumor size. In patients, serum calcitonin is the gold-standard biomarker of MTC, and it is now used to predict disease recurrence after surgical resection (Gawlik et al. 2010).

Gene expression signature of advanced MTC in older p27+/mut rats shares similarities with that of human MTCs carrying the RET-M918T mutation. RET-M918T has a very high transforming activity (Salvatore et al. 2001), and MTCs with this mutation (either germline or somatic) have an aggressive clinical course (Romei et al. 2016). Several of the genes concordantly differentially expressed in advanced vs early-stage rat MTCs and in RET-M918T vs RET-WT human tumors play a role in carcinogenesis but have not been implicated in MTC to date. A subset of these genes was validated by qRT-PCR in human tumors with different RET status and found to behave similarly to what was predicted by the expression array analysis. Among the genes specifically upregulated in RET-M918T tumors are TUBB2B and TUBB6 encoding $\beta$-tubulin class II or VI isotypes, respectively. $\beta$-Tubulins are a key component of microtubules, ubiquitous polymers critically involved in the mitotic phase of the cell cycle, intracellular transport, 
asymmetric morphology of neurons, ciliary and flagellar motility. While some isotypes are constitutively expressed (e.g. TUBB6), others, such as TUBB2B, are mostly restricted to neuronal tissues (Leandro-García et al. 2010). However, TUBB2 expression has been associated with unfavorable clinical parameters and poorer recurrencefree survival in bladder carcinoma (Choi et al. 2014), and it is a predictive marker of chemotherapy efficacy in breast cancer (Bernard-Marty et al. 2002). Class VI $\beta$-tubulin has not yet been extensively studied in cancer. NREP, coding for the P311 protein, was upregulated in RET-M918T cases. Noteworthy, NREP was listed among the genes upregulated in MEN2B vs MEN2A MTCs by Jain and coworkers (Jain et al. 2004), but no further validation was conducted. P311 promotes axonal regeneration, is highly expressed in invading glioblastoma cells (Mariani et al. 2001) and increases the motility of glioma cells through reorganization of actin cytoskeleton (McDonough et al. 2005). The high expression of these genes in RET-M918T MTCs is in agreement with transcriptome data showing that these tumors associate with an overrepresentation of signaling cascades related to invasion and metastasis (Maliszewska et al. 2013).

The genes predicted by array analysis to be less expressed in RET-M918T vs RET-WT were confirmed by qRT-PCR to be downregulated, albeit to a variable extent. These genes are also involved in cancer including HSPB1 (HSP27), that plays a role in therapy resistance and apoptosis in various solid tumors (Carra et al. 2017), and CLDN3, that is downregulated in lung cancer and associated with poor prognosis (Che et al. 2015). Noteworthy, these genes were highly expressed in RETC634 samples from MEN2A patients. Mutations at the C634 residue are associated with a relatively aggressive disease but less so than M918T mutations (Romei et al. 2016). In agreement with our qRT-PCR data, MTCs with C634 or M918T alterations have different gene expression signatures (Maliszewska et al. 2013, Oczko-Wojciechowska et al. 2017).

The genes described earlier may represent novel putative biomarkers of MTC progression and warrant further evaluation.

\section{p27 in MTC}

While germline activating mutations in RET virtually occur in all familial MTCs, somatic mutations occur in 23-70\% of the sporadic forms (Romei et al. 2016). Genes that control the cell cycle have been reported to contribute to the pathogenesis of MTC (Romei et al. 2016). For instance, loss of the retinoblastoma $(R b)$ gene in preclinical models causes CCH, which progresses to MTC (Harrison et al. 1995). Rb activity as tumor suppressor is regulated by CDKs and CDK inhibitors (e.g. p15, p18 and p27). Mice lacking $C d k n 2 c$ (p18) or $C d k n 1 b$ (p27) occasionally develop $\mathrm{CCH}$, which becomes much more frequent in the doubleknockout animals (Franklin et al. 2000). While somatic mutation of CDKN2C is present in $8 \%$ of human MTCs (http://cancer.sanger.ac.uk/cosmic) and its somatic loss associates with distant metastasis and decreased overall survival of sporadic MTC (Grubbs et al. 2016), much less is known of the role of p27 in human MTC. Two studies showed that the inheritance of polymorphisms in CDKN1B associates with the susceptibility to (Barbieri et al. 2014) or the prognosis of sporadic MTC (Pasquali et al. 2011). In vitro studies on fibroblasts demonstrated that activated RET (C634R mutation) represses the transcription of p27 (and p18), thereby suggesting that CDK inhibitors act downstream of active RET signaling (Joshi et al. 2007).

Our findings in MENX rats further support the concept that MTC can arise without the involvement of Ret, as it occurs in WAG/Rij rats, that spontaneously develop MTC with an incidence of about 50\% (De Miguel et al. 2003), and in transgenic mice with C-cells-targeted overexpression of $p 25$, activator of Cdk5 (Pozo et al. 2013). Noteworthy, both p 27 and Cdk5 target the $\mathrm{Rb}$ protein, although with opposing mechanisms. Indeed, p27 suppresses $\mathrm{Rb}$ phosphorylation by inhibiting Cdk2 activity, thereby stopping cell cycle progression (Lee \& Pellegata 2013). In contrast, Cdk5 phosphorylates $\mathrm{Rb}$ and promotes entry into the S-phase (Pozo et al. 2013). Consistent with their action on $\mathrm{Rb}, \mathrm{p} 27$ expression is mainly lost in NETs, whereas Cdk5 and its cofactors p25 and p35 are more highly expressed in NETs (Demelash et al. 2012, Xie et al. 2014), including MTC (Pozo et al. 2013), than in the corresponding normal tissues. Altogether, these findings support a critical role for cell cycle regulatory proteins in MTC development.

\section{Conclusion}

This study demonstrates that p27 is a haploinsufficient tumor suppressor in MENX rats and identifies p27+/mut animals as a new model of MTC, which recapitulates features of human MTC and shows progression to invasive and metastatic tumors. While surgical resection is often curative at the early stage of the disease and in low-grade MTCs, patients with advanced disease die from tumor progression. Given that about half of the patients show local invasion and distant metastases at the time 
of diagnosis (Roman et al. 2006) developing effective therapies for patients with advanced MTC is necessary. Targeted therapies using the multi-kinase inhibitors vandetanib and cabozantinib have demonstrated clinical benefit for patients with progressive or metastatic MTC; however, no changes in overall survival in patients were observed in phase III clinical trials (Wells et al. 2012, Elisei et al. 2013). p27+/mut rats might be a useful tool to elucidate the molecular pathogenesis of advanced MTCs and to identify novel therapeutic opportunities.

\section{Supplementary data}

This is linked to the online version of the paper at https://doi.org/10.1530/ ERC-17-0456

\section{Declaration of interest}

The authors declare that there is no conflict of interest that could be perceived as prejudicing the impartiality of the research reported.

\section{Funding}

This study was supported by grant SFB824-B08 from the Deutsche Forschungsgemeinschaft and grant \#70112383 from the Deutsche Krebshilfe to N S P. The Affymetrix platform is supported by grants from the Helmholtz Portfolio Theme 'Metabolic Dysfunction and Common Disease' and the Helmholtz Alliance 'Imaging and Curing Environmental Metabolic Diseases, ICEMED' to J B. Human samples were obtained thanks to Project PI14/00240 from Fondo de Investigaciones Sanitarias (FIS), Instituto de Salud Carlos III, co-financed by FEDER 2014-2020.

\section{Author contribution statement}

S M, A K, A F and T W conducted experiments; S M, M I, F N, J B, F R, M $R$ acquired and analyzed data; S M, A K, F R, N S P conceived the study, analyzed data, prepared figures and wrote the manuscript.

\section{Acknowledgements}

The authors thank E Pulz for technical support and E Samson for help with animal necropsies.

\section{References}

Barbieri RB, Bufalo NE, Secolin R, Assumpção LV, Maciel RM, Cerutti JM \& Ward LS 2014 Polymorphisms of cell cycle control genes influence the development of sporadic medullary thyroid carcinoma. European Journal of Endocrinology 171 761-767. (https://doi.org/10.1530/EJE14-0461)

Bencivenga D, Caldarelli I, Stampone E, Mancini FP, Balestrieri ML, Della Ragione F \& Borriello A 2017 p27Kip1 and human cancers: a reappraisal of a still enigmatic protein. Cancer Letters 403 354-365. (https://doi.org/10.1016/j.canlet.2017.06.031)

Bernard-Marty C, Treilleux I, Dumontet C, Cardoso F, Fellous A, Gancberg D, Bissery MC, Paesmans M, Larsimont D, Piccart MJ, et al. 2002 Microtubule-associated parameters as predictive markers of docetaxel activity in advanced breast cancer patients: results of a pilot study. Clinical Breast Cancer 3 341-345. (https://doi. org/10.3816/CBC.2002.n.037)

Besson A, Gurian-West M, Chen X, Kelly-Spratt KS, Kemp CJ \& Roberts JM 2006 A pathway in quiescent cells that controls p27Kip1 stability, subcellular localization, and tumor suppression. Genes and Development 20 47-64. (https://doi.org/10.1101/gad.1384406)

Brochier S, Galland F, Kujas M, Parker F, Gaillard S, Raftopoulos C, Young J, Alexopoulou O, Maiter D \& Chanson P 2010 Factors predicting relapse of nonfunctioning pituitary macroadenomas after neurosurgery: a study of 142 patients. European Journal of Endocrinology 163 193-200. (https://doi.org/10.1530/EJE-10-0255)

Cabanillas ME, McFadden DG \& Durante C 2016 Thyroid cancer. Lancet 388 2783-2795. (https://doi.org/10.1016/S0140-6736(16)30172-6)

Carra S, Alberti S, Arrigo PA, Benesch JL, Benjamin IJ, Boelens W, Bartelt-Kirbach B, Brundel BJ, Buchner J, Bukau B, et al. 2017 The growing world of small heat shock proteins: from structure to functions. Cell Stress and Chaperones 22 601-611. (https://doi. org/10.1007/s12192-017-0787-8)

Chandra M, Riley MG \& Johnson DE 1992 Spontaneous neoplasms in aged Sprague-Dawley rats. Archives of Toxicology 66 496-502. (https:// doi.org/10.1007/BF01970675)

Che J, Yang Y, Xiao J, Zhao P, Yan B, Dong S \& Cao B 2015 Decreased expression of claudin-3 is associated with a poor prognosis and EMT in completely resected squamous cell lung carcinoma. Tumour Biology 36 6559-6568. (https://doi.org/10.1007/s13277-015-3350-1)

Choi JW, Kim Y, Lee JH \& Kim YS 2014 Expression of $\beta$-tubulin isotypes in urothelial carcinoma of the bladder. World Journal of Urology 32 347-352. (https://doi.org/10.1007/s00345-012-0993-z)

Chu IM, Hengst L \& Slingerland JM 2008 The Cdk inhibitor p27 in human cancer: prognostic potential and relevance to anticancer therapy. Nature Reviews Cancer 8 253-267. (https://doi.org/10.1038/ nrc2347)

Cohen R, Campos JM, Salaun C, Heshmati HM, Kraimps JL, Proye C, Sarfati E, Henry JF, Niccoli-Sire P \& Modigliani E 2000 Preoperative calcitonin levels are predictive of tumor size and postoperative calcitonin normalization in medullary thyroid carcinoma. Groupe d'Etudes des Tumeurs a Calcitonine (GETC). Journal of Clinical Endocrinology and Metabolism 85 919-922. (https://doi.org/10.1210/ jcem.85.2.6556)

Crona J, Gustavsson T, Norlen O, Edfeldt K, Akerstrom T, Westin G, Hellman P, Bjorklund P \& Stalberg P 2015 Somatic mutations and genetic heterogeneity at the CDKN1B locus in small intestinal neuroendocrine tumors. Annals of Surgical Oncology 22 (Supplement 3) S1428-S1435. (https://doi.org/10.1245/s10434-014-4351-9)

Dahia PL 2014 Pheochromocytoma and paraganglioma pathogenesis: learning from genetic heterogeneity. Nature Reviews Cancer 14 108-119. (https://doi.org/10.1038/nrc3648)

Demelash A, Rudrabhatla P, Pant HC, Wang X, Amin ND, McWhite CD, Naizhen X \& Linnoila RI 2012 Achaete-scute homologue-1 (ASH1) stimulates migration of lung cancer cells through Cdk5/p35 pathway. Molecular Biology of the Cell 23 2856-2866. (https://doi. org/10.1091/mbc.E10-12-1010)

De Miguel M, Fernández-Santos JM, Trigo-Sánchez I, Matera I, Ceccherini I, Martín I, Romeo G \& Galera-Davidson H 2003 The Ret proto-oncogene in the $\mathrm{WAG} / \mathrm{Rij}$ rat strain: an animal model for inherited C-cell carcinoma? Laboratory Animals 37 215-221. (https:// doi.org/10.1258/002367703766453065)

Doghman M, Figueiredo BC, Volante M, Papotti M \& Lalli E 2013 Integrative analysis of SF-1 transcription factor dosage impact on genome-wide binding and gene expression regulation. Nucleic Acids Research 41 8896-8907. (https://doi.org/10.1093/nar/gkt658)

Durante C, Paciaroni A, Plasmati K, Trulli F, \& Filetti S 2013 Vandetanib: opening a new treatment practice in advanced medullary thyroid carcinoma. Endocrine 44 334-342. (https://doi.org/10.1007/s12020013-9943-9) http://erc.endocrinology-journals.org https://doi.org/10.1530/ERC-17-0456
(2) 2018 Society for Endocrinology Published by Bioscientifica Ltd. Printed in Great Britain 
Eisenhofer G, Bornstein SR, Brouwers FM, Cheung NK, Dahia PL, de Krijger RR, Giordano TJ, Greene LA, Goldstein DS, Lehnert H, et al. 2004 Malignant pheochromocytoma: current status and initiatives for future progress. Endocrine-Related Cancer 11 423-436. (https://doi. org/10.1677/erc.1.00829)

Elisei R, Cosci B, Romei C, Bottici V, Renzini, G, Molinaro E, Agate L, Vivaldi A, Faviana P, Basolo F, et al. 2008 Prognostic significance of somatic RET oncogene mutations in sporadic medullary thyroid cancer: a 10-year follow-up study. Journal of Clinical Endocrinology and Metabolism 93 682-687. (https://doi.org/10.1210/jc.2007-1714)

Elisei R, Schlumberger MJ, Müller SP, Schöffski P, Brose MS, Shah MH, Licitra L, Jarzab B, Medvedev V, Kreissl MC, et al. 2013 Cabozantinib in progressive medullary thyroid cancer. Journal of Clinical Oncology 31 3639-3646. (https://doi.org/10.1200/JCO.2012.48.4659)

Fero ML, Rivkin M, Tasch M, Porter P, Carow CE, Firpo E, Polyak K, Tsai LH, Broudy V, Perlmutter RM, et al. 1996 A syndrome of multiorgan hyperplasia with features of gigantism, tumorigenesis, and female sterility in p27(Kip1)-deficient mice. Cell 85 733-744. (https://doi.org/10.1016/S0092-8674(00)81239-8)

Fero ML, Randel E, Gurley KE, Roberts JM \& Kemp CJ 1998 The murine gene p27Kip1 is haplo-insufficient for tumour suppression. Nature 396 177-180. (https://doi.org/10.1038/24179)

Francis JM, Kiezun A, Ramos AH, Serra S, Pedamallu CS, Qian ZR, Banck MS, Kanwar R, Kulkarni AA, Karpathakis A, et al. 2013 Somatic mutation of CDKN1B in small intestine neuroendocrine tumors. Nature Genetics 45 1483-1486. (https://doi.org/10.1038/ng.2821)

Franklin DS, Godfrey VL, O'Brien DA, Deng C \& Xiong Y 2000 Functional collaboration between different cyclin-dependent kinase inhibitors suppresses tumor growth with distinct tissue specificity. Molecular and Cellular Biology 20 6147-6158. (https://doi. org/10.1128/MCB.20.16.6147-6158.2000)

Fritz A, Walch A, Piotrowska K, Rosemann M, Schaffer E, Weber K, Timper A, Wildner G, Graw J, Hofler H, et al. 2002 Recessive transmission of a multiple endocrine neoplasia syndrome in the rat. Cancer Research 62 3048-3051.

Gao H, Ouyang X, Banach-Petrosky W, Borowsky AD, Lin Y, Kim M, Lee H, Shih WJ, Cardiff RD, Shen MM, et al. 2004 A critical role for p27kip1 gene dosage in a mouse model of prostate carcinogenesis. PNAS 101 17204-17209. (https://doi.org/10.1073/pnas.0407693101)

Gawlik T, d'Amico A, Szpak-Ulczok S, Skoczylas A, Gubała E, Chorąży A, Gorczewski K, Włoch J \& Jarząb B 2010 The prognostic value of tumor markers doubling times in medullary thyroid carcinoma preliminary report. Thyroid Research 3 10. (https://doi. org/10.1186/1756-6614-3-10)

Grubbs EG, Williams MD, Scheet P, Vattathil S, Perrier ND, Lee JE Gagel RF, Hai T, Feng L, Cabanillas ME, et al. 2016 Role of CDKN2C copy number in sporadic medullary thyroid carcinoma. Thyroid 26 1553-1562. (https://doi.org/10.1089/thy.2016.0224)

Harrison DJ, Hooper ML, Armstrong JF \& Clarke AR 1995 Effects of heterozygosity for the Rb-1t19neo allele in the mouse. Oncogene 10 1615-1620.

Jain S, Watson MA, DeBenedetti MK, Hiraki Y, Moley JF \& Milbrandt J 2004 Expression profiles provide insights into early malignant potential and skeletal abnormalities in multiple endocrine neoplasia type 2B syndrome tumors. Cancer Research 64 3907-3913. (https:// doi.org/10.1158/0008-5472.CAN-03-3801)

Jeannot P, Callot C, Baer R, Duquesnes N, Guerra C, GuillermetGuibert J, Bachs O \& Besson A 2015 Loss of p27Kip ${ }^{1}$ promotes metaplasia in the pancreas via the regulation of Sox9 expression. Oncotarget 6 35880-35892. (https://doi.org/10.18632/ oncotarget.5770)

Joshi PP, Kulkarni MV, Yu BK, Smith KR, Norton DL, van Veelen W, Höppener JW \& Franklin DS 2007 Simultaneous downregulation of CDK inhibitors p18(Ink4c) and p27(Kip1) is required for MEN2ARET-mediated mitogenesis. Oncogene 26 554-570. (https://doi. org/10.1038/sj.onc.1209811)
Kiyokawa H, Kineman RD, Manova-Todorova KO, Soares VC, Hoffman ES, Ono M, Khanam D, Hayday AC, Frohman LA \& Koff A 1996 Enhanced growth of mice lacking the cyclin-dependent kinase inhibitor function of p27(Kip1). Cell 85 721-732. (https://doi. org/10.1016/S0092-8674(00)81238-6)

Kurzrock R, Sherman SI, Ball DW, Forastiere AA, Cohen RB, Mehra R, Pfister DG, Cohen EE, Janisch L, Nauling F, et al. 2011 Activity of XL184 (Cabozantinib), an oral tyrosine kinase inhibitor, in patients with medullary thyroid cancer. Journal of Clinical Oncology 29 2660-2666. (https://doi.org/10.1200/JCO.2010.32.4145)

Leandro-García LJ, Leskelä S, Landa I, Montero-Conde C, LópezJiménez E, Letón R, Cascón A, Robledo M \& Rodríguez-Antona C 2010 Tumoral and tissue-specific expression of the major human beta-tubulin isotypes. Cytoskeleton 67 214-223. (https://doi. org/10.1002/cm.20436)

Lee M, Marinoni I, Irmler M, Psaras T, Honegger JB, Beschorner R, Anastasov N, Beckers J, Theodoropoulou M, Roncaroli F, et al. 2013 Transcriptome analysis of MENX-associated rat pituitary adenomas identifies novel molecular mechanisms involved in the pathogenesis of human pituitary gonadotroph adenomas. Acta Neuropathologica 126 137-150. (https://doi.org/10.1007/s00401-013-1132-7)

Lee M \& Pellegata NS 2013 Multiple endocrine neoplasia type 4. Frontiers of Hormone Research 41 63-78.

Lee M, Wiedemann T, Gross C, Roncaroli F, Braren R \& Pellegata NS 2015 Targeting PI3K/mTOR signaling displays potent antitumor efficacy against nonfunctioning pituitary adenomas. Clinical Cancer Research 21 3204-3215. (https://doi.org/10.1158/1078-0432.CCR-15-0288)

Lee M, Minaskan N, Wiedemann T, Irmler M, Beckers J, Yousefi BH, Kaissis G, Braren R, Laitinen I \& Pellegata NS 2017 The norepinephrine transporter as a putative predictive biomarker for PI3K/mTOR inhibition in pheochromocytoma. Endocrine-Related Cancer 24 1-15. (https://doi.org/10.1530/ERC-16-0324)

Lloyd RV, Kovacs K, Young WF Jr, Farrell W, Asa SL, Trouillas J, Kontogeorgos G \& Sano T 2004 Pituitary tumors: introduction. In Pathology and Genetics of Tumours of Endocrine Organs, pp 10-13. Eds RA DeLellis, RV Lloyd, PU Heitz \& C Eng. Lyon, France: IARC Press.

Maliszewska A, Leandro-Garcia LJ, Castelblanco E, Macia A, de Cubas A, Gomez-Lopez G, Inglada-Perez L, Alvarez-Escola C, De la Vega L, Leton R, et al. 2013 Differential gene expression of medullary thyroid carcinoma reveals specific markers associated with genetic conditions. American Journal of Pathology 182 350-362. (https://doi. org/10.1016/j.ajpath.2012.10.025)

Mariani L, McDonough WS, Hoelzinger DB, Beaudry C, Kaczmarek E, Coons SW, Giese A, Moghaddam M, Seiler RW \& Berens ME 2001 Identification and validation of P311 as a glioblastoma invasion gene using laser capture microdissection. Cancer Research $\mathbf{6 1}$ 4190-4196.

Marinoni I, Lee M, Mountford S, Perren A, Bravi I, Jennen L, Feuchtinger A, Drouin J, Roncaroli F \& Pellegata NS 2013 Characterization of MENX-associated pituitary tumours. Neuropathology and Applied Neurobiology 39 256-269. (https://doi. org/10.1111/j.1365-2990.2012.01278.x)

Maxwell JE, Sherman SK, Li G, Choi AB, Bellizzi AM, O'Dorisio TM \& Howe JR 2015 Somatic alterations of CDKN1B are associated with small bowel neuroendocrine tumors. Cancer Genetics 28 564-570. (https://doi.org/10.1016/j.cancergen.2015.08.003)

McComb DJ, Kovacs K, Beri J \& Zak F 1984 Pituitary adenomas in old Sprague-Dawley rats: a histologic, ultrastructural, and immunocytochemical study. Journal of the National Cancer Institute 73 1143-1166.

McDonough WS, Tran NL \& Berens ME 2005 Regulation of glioma cell migration by serine-phosphorylated P311. Neoplasia 7 862-872. (https://doi.org/10.1593/neo.05190)

Molatore S, Kiermaier E, Jung CB, Lee M, Pulz E, Hofler H, Atkinson MJ \& Pellegata NS 2010a Characterization of a naturally-occurring p27 http://erc.endocrinology-journals.org https://doi.org/10.1530/ERC-17-0456 (c) 2018 Society for Endocrinology Published by Bioscientifica Ltd. Printed in Great Britain 
mutation predisposing to multiple endocrine tumors. Molecular Cancer 9 116. (https://doi.org/10.1186/1476-4598-9-116)

Molatore S, Liyanarachchi S, Irmler M, Perren A, Mannelli M, Ercolino T, Beuschlein F, Jarzab B, Wloch J, Ziaja J, et al. 2010 b Pheochromocytoma in rats with multiple endocrine neoplasia (MENX) shares gene expression patterns with human pheochromocytoma. PNAS 107 18493-18498. (https://doi. org/10.1073/pnas.1003956107)

Muraoka RS, Lenferink AE, Law B, Hamilton E, Brantley DM, Roebuck LR \& Arteaga CL 2002 ErbB2/Neu-induced, cyclin D1-dependent transformation is accelerated in p27-haploinsufficient mammary epithelial cells but impaired in p27-null cells. Molecular and Cellular Biology 22 2204-2219. (https://doi.org/10.1128/ МСB.22.7.2204-2219.2002)

Nakayama K, Ishida N, Shirane M, Inomata A, Inoue T, Shishido N, Horii I, Loh DY \& Nakayama K 1996 Mice lacking p27(Kip1) display increased body size, multiple organ hyperplasia, retinal dysplasia, and pituitary tumors. Cell 85 707-720. (https://doi.org/10.1016/ S0092-8674(00)81237-4)

Nakazawa M, Tawaratani T, Uchimoto H, Kawaminami A, Ueda M, Ueda A, Shinoda Y, Iwakura K, Kura K \& Sumi N 2001 Spontaneous neoplastic lesions in aged Sprague-Dawley rats. Experimental Animals 50 99-103. (https://doi.org/10.1538/expanim.50.99)

Niwa H, Miyazaki J \& Smith AG 2000 Quantitative expression of Oct$3 / 4$ defines differentiation, dedifferentiation or self-renewal of ES cells. Nature Genetics 24 372-376. (https://doi.org/10.1038/74199)

Oczko-Wojciechowska M, Swierniak M, Krajewska J, Kowalska M, Kowal M, Stokowy T, Wojtas B, Rusinek D, Pawlaczek A, Czarniecka A, et al. 2017 Differences in the transcriptome of medullary thyroid cancer regarding the status and type of RET gene mutations. Scientific Reports 7 42074. (https://doi.org/10.1038/ srep42074)

Ohji H, Sasagawa I, Iciyanagi O, Suzuki Y \& Nakada T 2001 Tumour angiogenesis and Ki-67 expression in phaeochromocytoma. BJU International 87 381-385. (https://doi. org/10.1046/j.1464-410x.2001.00102.x)

Park MS, Rosai J, Nguyen HT, Capodieci P, Cordon-Cardo C \& Koff A 1999 p27 and $\mathrm{Rb}$ are on overlapping pathways suppressing tumorigenesis in mice. PNAS 96 6382-6387. (https://doi. org/10.1073/pnas.96.11.6382)

Pasquali D, Circelli L, Faggiano A, Pancione M, Renzullo A, Elisei R, Romei C, Accardo G, Coppola VR, De Palma M, et al. 2011 CDKN1B V109G polymorphism a new prognostic factor in sporadic medullary thyroid carcinoma. European Journal of Endocrinology 164 397-404. (https://doi.org/10.1530/EJE-10-0929)

Pellegata NS, Quintanilla-Martinez L, Siggelkow H, Samson E, Bink K, Hofler H, Fend F, Graw J \& Atkinson MJ 2006 Germ-line mutations in p27Kip1 cause a multiple endocrine neoplasia syndrome in rats and humans. PNAS 103 15558-15563. (https://doi.org/10.1073/ pnas.0603877103)

Pereira AM \& Biermasz NR 2012 Treatment of nonfunctioning pituitary adenomas: what were the contributions of the last 10 years? A critical view. Annales d'Endocrinologie 73 111-116. (https://doi. org/10.1016/j.ando.2012.04.002)

Pippa R, Espinosa L, Gundem G, Garcia-Escudero R, Dominguez A, Orlando S, Gallastegui E, Saiz C, Besson A, Pujol MJ, et al. 2012
p27Kip1 represses transcription by direct interaction with p130/E2F4 at the promoters of target genes. Oncogene 31 4207-4220. (https:// doi.org/10.1038/onc.2011.582)

Pozo K, Castro-Rivera E, Tan C, Plattner F, Schwach G, Siegl V, Meyer D, Guo A, Gundara J, Mettlach G, et al. 2013 The role of Cdk5 in neuroendocrine thyroid cancer. Cancer Cell 24 499-511. (https://doi. org/10.1016/j.ccr.2013.08.027)

R Development Core Team 2011 R: A Language and Environment for Statistical Computing. Vienna, Austria: The R Foundation for Statistical Computing.

Rainer J, Sanchez-Cabo F, Stocker G, Sturn A \& Trajanoski Z 2006 CARMAweb: comprehensive R- and bioconductor-based web service for microarray data analysis. Nucleic Acids Research 34 W498-W503. (https://doi.org/10.1093/nar/gkl038)

Raue F \& Frank-Raue K 2009 Genotype-phenotype relationship in multiple endocrine neoplasia type 2 . Implications for clinical management. Hormones 8 23-28. (https://doi.org/10.14310/ horm.2002.1218)

Rendl G, Manzl, M, Hitzl W, Sungler P \& Pirich C 2008 Long-term prognosis of medullary thyroid carcinoma. Clinical Endocrinology 69 497-505. (https://doi.org/10.1111/j.1365-2265.2008.03229.x)

Roman S, Lin R \& Sosa JA 2006 Prognosis of medullary thyroid carcinoma: demographic, clinical, and pathologic predictors of survival in 1252 cases. Cancer 107 2134-2142. (https://doi. org/10.1002/cncr.22244)

Romei C, Ciampi R \& Elisei R 2016 A comprehensive overview of the role of the RET proto-oncogene in thyroid carcinoma. Nature Reviews Endocrinology 12 192-202. (https://doi.org/10.1038/nrendo.2016.11)

Salvatore D, Melillo RM, Monaco C, Visconti R, Fenzi G, Vecchio G, Fusco A \& Santoro M 2001 Increased in vivo phosphorylation of ret tyrosine 1062 is a potential pathogenetic mechanism of multiple endocrine neoplasia type 2B. Cancer Research 61 1426-1431.

Sato Y, Suto Y, Pietenpol J, Golub TR, Gilliland DG, Davis EM, Le Beau MM, Roberts JM, Vogelstein B, Rowley JD, et al. 1995 TEL and KIP1 define the smallest region of deletions on 12p13 in hematopoietic malignancies. Blood 86 1525-1533.

Vitale G, Gaudenzi G, Circelli L, Manzoni MF, Bassi A, Fioritti N, Faggiano A, Colao A \& NIKE Group 2017 Animal models of medullary thyroid cancer: state of the art and view to the future. Endocrine-Related Cancer 24 R1-R12. (https://doi.org/10.1530/ERC-160399)

Wells SA Jr, Robinson BG, Gagel RF, Dralle H, Fagin JA, Santoro M, Baudin E, Elisei R, Jarzab B, Vasselli JR, et al. 2012 Vandetanib in patients with locally advanced or metastatic medullary thyroid cancer: a randomized, double-blind phase III trial. Journal of Clinical Oncology 30 134-141. (https://doi.org/10.1200/JCO.2011.35.5040)

Wiedemann T \& Pellegata NS 2016 Animal models of multiple endocrine neoplasia. Molecular and Cellular Endocrinology 421 49-59. (https://doi.org/10.1016/j.mce.2015.07.004)

Woyach JA \& Shah MH 2009 New therapeutic advances in the management of progressive thyroid cancer. Endocrine-Related Cancer 16 715-731. (https://doi.org/10.1677/ERC-08-0335)

Xie W, Wang H, He Y, Li D, Gong L \& Zhang Y 2014 CDK5 and its activator P35 in normal pituitary and in pituitary adenomas: relationship to VEGF expression. International Journal of Biological Sciences 10 192-199. (https://doi.org/10.7150/ijbs.7770)

Received in final form 9 November 2017

Accepted 15 November 2017

Accepted Preprint published online 15 November 2017 http://erc.endocrinology-journals.org https://doi.org/10.1530/ERC-17-0456 (c) 2018 Society for Endocrinology Published by Bioscientifica Ltd. Printed in Great Britain 